$\underline{\text { Alfredo Corpaci }}$

\title{
Reformas en la \\ laboralización de la relación de empleo público en Italia: aspectos constitucionales y referencia a la normativa más reciente
}

SUMARIO: 1. LA .CONFIGURACIÓN TRADICIONAL DEL EMPLEO PÚBLICCO. 2. LOS PROBLEMAS CONSTITUCIONALES. 3. EL PROCESO DE REVISIÓN LEGISLATIVA: LA LEY MARCO DE 1983. 4. LA REFORMA DE 1992-1993. UNA ADVERTENCIA PREVLA. 5. LA PRIVATIZACIÓN-CONTRACTUALIZACIÓN DEL EMPLEO CON LAS ADMMNISTRACIONES PÚBLICAS. 6. LOS ASPECTOS PROBLEMÁTICOS DE LA REFORMA: LA COHERENCIA DE LA APLICACIÓN DE UN REGIMEN PRIVADO CON LOS PRINCIPIOS CONSTITUCIONALES. 7. (CONTINUACIÓN) ASPECTOS CRÍTICOS SOBRE ALGUNOS LIMITES Y MODALIDADES DE LA CONTRACTUALIZACIÓN DEL EMPLEO.

\section{LA CONFIGURACIÓN TRADICIONAL DEL EMPLEO PÚBLICO}

La configuración tradicional del empleo público en Italia es fruto, más que de la reflexión doctrinal, de la labor de los jueces.

Ya a mediados de los años treinta V. E. OrLando, estudioso "considerado por la mayoría como el padre fundador del iuspublicismo italiano" ${ }^{1}$, lamentaba la escasez y las lagunas de las

Artículo traducido por Josefa Cantero Martinez, Becaria F.P.I. Universidad de Castilla-La Mancha.

'M. Foravanti, "Costituzione, amministrazione e trasformazioni dello Stato", en Stato e cultura giuridica in Italia, dell'unita alla repubblica, obra dirigida por A. Schiavone, Bari, 1990, 13.

Documentación Administrativa / n. 243 (septiembre-diciembre 1995) 
contribuciones científicas sobre el tema ${ }^{2}$. Pero también sucesivamente, y durante mucho tiempo, la literatura, salvo raras excepciones, resultó prevalentemente orientada a la exégesis de las normas y a objetivos prácticos-profesionales ${ }^{3}$.

Por otra parte, el mismo dato normativo, formado por estratificaciones sucesivas y por intervenciones sectoriales, ha constituido un punto de referencia más que decisivo. La primera regulación orgánica del empleo estatal se produjo en $1908^{4}$, mientras que para la regulación del empleo en los entes locales es una ley de $1902^{5}$ la que dicta por vez primera una disciplina relativamente completa. En este sentido, es preciso resaltar que diez años antes había sido atribuida al juez administrativo local la decisión, entre otras, de los recursos de los empleados provinciales y comunales relacionados con los actos de despido, imposición de sanciones disciplinarias, licencias del servicio y, más en general, sobre los procedimientos relativos a la carrera 6. En el empleo local, por tanto, la regulación de la tutela jurisdiccional precede a una completa disciplina de los aspectos sustanciales.

El suceso recién indicado es significativo de la importante incidencia que ha tenido en esta materia la cuestión de la tutela jurisdiccional. En relación con dicha cuestión, y más en particular con ocasión de la determinación del juez competente para conocer de las controversias entre la Administración pública y sus empleados, se ha ido formando por obra principalmente de la jurisprudencia la configuración tradicional de la relación de empleo público.

En el ordenamiento italiano, con la Ley de 20 de marzo de 1865, núm. 2248, de abolición del contencioso administrativo, fueron traspasadas al juez ordinario todas las controversias de las Administraciones públicas referidas a los derechos subjetivos; todos los litigios en los que no estuviera en juego un derecho subjetivo fueron reservados a las autoridades administrativas. Inicialmente (hasta 1877) tuvo que intervenir el Consejo de Estado para trazar la línea separadora del área en la que había sido concedida acción ante el juez y el área reservada a la Administración.

${ }^{2}$ V. E. OrLANDo, «ll rapporto di pubblico impiego, a proposito di una recente pubblicazione", Riv. Dir. Pubbl, 1935, I, 623 y ss.

${ }^{3}$ Cfr. A. Corpaci, «La cultura giuridica e il problema del pubblico impiego dal 1909 al 1930: spunti dalle rivistem, Riv. Trim. Dir. Pubbl., 1977, 1253 y ss.

4 Ley de 24 de junio de 1908, núm. 290, más tarde recogida en el T. U. de 22 de noviembre de 1908, núm. 693.

${ }^{5}$ Ley de 7 de mayo de 1902, núm. 144.

${ }^{6}$ Artículos 1 y 2 de la Ley de 1 de mayo de 1890, núm. 6837. 
Precisamente en el ejercicio de tal función el Consejo de Estado se pronunció en el sentido de que las controversias promovidas por los empleados estatales deberian considerarse por su naturaleza sustraídas a la jurisdicción del juez ${ }^{7}$. Se consideraba que la relación de empleo estaba regulada en «leyes administrativas» relativas al ordenamiento y a la regulación del aparato administrativo y, como tales, «de orden puramente administrativo y concernientes a la justicia distributivan, remitidas para su actuación y ejecución a la misma autoridad administrativa ${ }^{8}$. La interferencia del juez era considerada como un atentado a las prerrogativas irrenunciables de la Administración, de tal manera que de ello se temía un doble orden de efectos negativos: por una parte, un perjuicio a la independencia de la Administración $y$, por otra, una perturbación en el funcionamiento de los servicios públicos ${ }^{9}$.

La Casación en Secciones Unidas, a quien fue atribuida a partir de 1877 la función de juez de los conflictos entre autoridad judicial y Administración, corrigió sólo en parte la línea jurisprudencial marcada previamente por el Consejo de Estado. La Casación admitió, efectivamente, la subsistencia de un «verdadero derecho civilsy, por tanto, la tutela ante el juez ordinario, en aquellos casos en los que la pretensión del empleado se fundaba sobre una puntual norma de ley cuya aplicación no dejaba espacio a valoraciones discrecionales de la Administración. Pero, fuera de estos casos, confirmó que los actos y las determinaciones relativas a los empleados públicos debían considerarse incluidas dentro de la tutela «de los intereses generales»y, por tanto, no sujetas a las reglas del Derecho civil ni al control de la autoridad judicial ${ }^{10}$.

Instituido en 1889/1890 el juez administrativo, la antedicha orientación servirá como criterio para el reparto de las controversias entre la autoridad judicial ordinaria y el nuevo juez. El reconocimiento de la jurisdicción de uno o de otro se hizo depender de la circunstancia de que el juicio implicara o no la valoración del aspecto discrecional del acto adoptado por la Administración ${ }^{11}$. Por otra parte, por el hecho mismo de la presencia

\footnotetext{
${ }^{7}$ Cfr. Cons. Stato, decreto su conflitto, 26 de abril de 1871, en Legge, 1871, II, 164.

8 Cfr. Cons. Stato, decreto su conflitto, 2 de julio de 1868, en Legge, 1868, II, 346; Id. 26 de abril de 1871, ivi, 1871, II, 164; Id. 2 de julio de 1870, en Riv. Amm., 1870, 897.

${ }^{9}$ Cfr. Cons. Stato, decreto su conflitto, 5 de julio de 1873, en Legge, 1873, II, 276; Id. 15 de mayo de 1875, en Giur. It., 1875, II, 60.

${ }^{10}$ Cfr. Cass. Roma, Sezioni Unite, 3 de enero de 1880, núm. 1, en Conte Supr. Roma, 1880, 283.

${ }^{11}$ Cfr., ad es., Cass. Roma, 8 de junio de 1903, en Giur. It, 1903, I, 1, 561, en la que es admitida la acción ante el juez ordinario en un litigio sobre un procedimiento disciplinario en el que se denunciaba la ilegitimidad por su oposición con tasadas disposiciones de ley.
} 
del nuevo juez, la jurisprudencia ordinaria retrocedió en ciertas posiciones que antes habia adoptado con la intención de salvaguardar determinados intereses de los empleados que de otra manera hubieran quedado privados de tutela ${ }^{12}$. Es así como se fueron adoptando con mayor frecuencia determinadas decisiones según las cuales las posiciones de los empleados no eran justiciables ante la autoridad judicial ordinaria; ello se argumentaba afirmando que dichas posiciones encontraban su apoyo en leyes y normas de orden público cuya aplicación debía considerarse «confiada a la superior jerarquía administrativa y debía ser guiada por criterios prevalentes de utilidad públicas ${ }^{13}$.

Es, efectivamente, la idea del relieve que asume en esta materia el interés público, la idea de que el susodicho interés «es tan prevalente y absorbente como para hacer desaparecer o debilitar el alcance efectivo de la cuestión patrimonial o de Derecho privado» ${ }^{14}$ lo que determinó en 1923 la unificación de la jurisdicción en materia de empleo público ante el juez administrativo.

En el mismo año es dictada por el primer ministro Mussolini una nueva regulación sobre el status jurídico de los empleados civiles del Estado; explícita premisa es que «la relación de empleo no es una simple prestación de trabajo... sino una relación ética en virtud de la cual el empleado es admitido en la Administración» 15. En consonancia con el clima político de la época la nueva regulación pone fuertemente el acento sobre el deber de fidelidad, exigiendo al empleado público una plena sujeción a las directivas políticas del Gobierno ${ }^{16}$. Pero al margen de tales manifestaciones, que son debidas principalmente a la ideología entonces dominante, la nueva regulación resalta la idea, ya extensamente difundida con anterioridad, de que el empleo público, siendo intrínseco a la organización administrativa $e$ instrumental respecto al funcionamiento de la Administración, requiere un régimen de

12 Cfr. G. Mrele, «La giustizia amministrativa, en La giustizia amministrativa, obra dirigida por G. Miele, Atti del Convegno celebrativo del centenario delle leggi ammnistrative di unificazione, Venecia, $1968,26$.

${ }^{13}$ Cass. Roma, 17 de enero de 1903, en Giur. It., 1903, I, 1, 1144.

14 Exposición de motivos del Real Decreto de 30 de diciembre de 1923, núm. 2840, en Gart: Uff., 8 de enero de 1924, num. 6, 77.

15 Exposición de motivos del Real Decreto de 30 de diciembre de 1923, núm. 2960 sobre el status jurídico de los empleados civiles del Estado.

16 El artículo 51 del Real Decreto núm. 2960 de 1923 cit. (modificado por el Real Decreto de 6 de enero de 1927, núm. 57 y extendido a los empleados de los entes locales con el Real Decreto Legislativo de 30 de enero de 1927, núm. 214) preveía la separación del servicio del empleado que upor manifestaciones realizadas en el oficio o fuera del oficio no diera plena garantia de un fiel cumplimiento de sus deberes y se pusiera en condiciones de incompatibilidad con las generales directivas políticas del Gobiernom. 
Derecho público ${ }^{17}$ que garantice su funcionalización a aquella del interés público, a cuya satisfacción está destinada la Administración misma.

De ello se deriva el rechazo a las concepciones contractualistas que, por el contrario, pretendían recalcar la simetría y las semejanzas con el trabajo privado ${ }^{18}$. La relación de empleo público se opone a la teoria contractualista por su pertenencia a la organización administrativa, es regulada unilateralmente por normas de Derecho objetivo y es objeto del poder público que tiene toda Administración pública para dotarse a sí misma de su propia organización.

El sometimiento al juez administrativo de las controversias en esta materia ${ }^{19}$ constituye un decisivo soporte para tal conclusión. La atribución de la tutela al juez del poder público, si por un lado es presentada como una confirmación del hecho de que «la relación e empleo público en su conjunto es ciertamente una relación con potestad de imperion ${ }^{20}$, por otro lado, constituye un elemento determinante para tal configuración.

La idea de que el trabajo en las Administraciones públicas asume una especial connotación en razón de su inserción en la organización administrativa y de su sujeción al régimen y a las reglas propias de esta última encuentra apoyo en las propias normas. Ya la más antigua legislación ${ }^{21}$ unía la regulación del empleo a la previsión de que «los ministros dotaran la Administración central del Estado de oficios sometidos a su inmediata dependencia»; especificando que «la organización de los ministerios y de los oficios... tendría lugar de manera uniforme en cuanto a títulos, grados y remuneraciones del personal». En aplicación

17 O. RANeLLet7, «Le categorie del personale al servizio dello Statom, en Foro Italiano, 1938, IV, 41, configura la relación entre Estado y empleado en términos de relación orgánica de sujeción de Derecho público: en la medida en que el empleado es encuadrado en la organización administrativa, la disciplina del empleo no puede gozar de una propia autonomía respecto a la más general de la organización administrativa, de la cual no es sino un aspecto.

18 Cfr. V. E. Orlando, «Relazione alla Camera dei Deputati sulla proposta di legge "contratto di lavoro di impiegati di aziende private e commessi di commercio"", en Scritti vari di diritto pubblico e scienza politica, Milán, 1940, 172; asi como del mismo autor, «Il rapporto di pubblico impiegon, cit.

${ }^{19} \mathrm{La}$ unificación de la tutela ante el juez administrativo le ha permitido proceder a una reconstrucción unitaria de la materia (cfr. M. S. GIANNINI, «Impiego pubblico. Profili storici e teoricis, en Enc. Dir., XX, Milán, 1970, 298) acentuando la dependencia del aspecto laboral de aquel relativo a las modalidades organizativos de la Administración pública, privilegiando la garantía objetivo-formal de la legalidad respecto a aquella subjetiva del empleado como prestador de trabajo (v. al respecto las críticas de M. Rusciano, L'impiego pubblico in Italia, Bolonia, 1978).

${ }_{20} \mathrm{G}$. FAGIOLARI, «L'atto amministrativo nella giustizia amministrativa», en Scritti in onore de S. Romano, vol. II, Padua, 311 .

21 Cfr. la Ley de 23 de marzo de 1853 sobre la Administración central del Estado y el consiguiente reglamento aprobado por el Real Decreto de 23 de noviembre de 1853. 
de tales principios, de un lado, se estaba reservando a la ley la determinación de las remuneraciones $y$, por otro, se estaba reenviando al reglamento la especificación de los «títulos y grados, así como también de otras bases de organización».

Esta previsión, que será seguida por la Ley orgánica sobre los empleados civiles del Estado de 1908 y posteriormente por la normativa de 1923 antes mencionada, comporta la consideración del empleado público no como uno de los sujetos de una relación de intercambio de trabajo-salario, sino más bien como un elemento del aparato administrativo. La relación de empleo viene de esta forma referida, más que a las reglas del trabajo, a las normas de la organización administrativa en la cual se inserta su prestación; la subordinación del empleado público se califica, por tanto, no como «debitoria» sino como organizativa ${ }^{22}$ y se concreta en los procedimientos a través de los cuales la Administración, en el ejercicio de sus potestades públicas, se encarga de su propia organización.

Es preciso resaltar que el elemento fundamental de toda esta construcción es el hecho de la inserción de la prestación laboral en el aparato de la Administración pública, sin que tenga relevancia alguna la circunstancia por la cual el empleado es investido, ni la titularidad del oficio que se le confia, ni el ejercicio de funciones públicas. La especialidad del régimen del empleo público se basa, pues, no ya en el tipo o la sustancia o en la particular cualificación de la prestación, sino en el estar insertada dicha prestación en el aparato administrativo. La especialidad del régimen, por tanto, se extiende en principio a todo el trabajo subordinado en las Administraciones públicas, sin distinguir entre empleados sujetos al ejercicio de potestades públicas y los empleados que realizan funciones meramente ejecutivas o materiales.

Por otra parte, es preciso advertir que desde 1923 se ha venido desarrollando un proceso normativo que al final ha producido una reducción del área de los empleados de las Administraciones públicas en régimen de empleo público. Tal proceso ha tenido su origen histórico en la progresiva reconducción al ámbito de la organización sindical corporativa fascista de los entes públicos dedicados, ya sea exclusiva o prevalentemente, al desarrollo de la actividad económica, y se perfeccionó en 1941 con una ley que atribuia a la autoridad judicial ordinaria la jurisdicción sobre las controversias individuales o colectivas relativas a las relaciones

22 Cfr. E. Ghera, «Lavoro e organizzazione amministrativa», en Riv. Trim. Dir. Pubbl., 1975, 43 y ss. 
de trabajo y de empleo de los empleados de los entes públicos encuadrados en las asociaciones sindicales ${ }^{23}$.

Dicha solución permaneció también tras la caída de la organización sindical fascista. Se ha intentado justificar apelando a las diferencias estructurales entre sujetos públicos dedicados al desarrollo de la actividad administrativa y sujetos públicos destinados al desarrollo exclusivo o prevalente de una actividad económica. Estos últimos, en la medida en que ejercitan una actividad de producción para el mercado y de intermediación en el intercambio, asumen una forma de organización y de gestión que sustancialmente se corresponde con aquella que es propia de una empresa; para ellos el fin público queda como «elemento funcional extrínseco", no incidiendo sobre el tipo de organización ni sobre las modalidades operativas, sino que, por el contrario, están marcados, al igual que los empresarios privados, por las reglas del mercado y de la iniciativa económica ${ }^{24}$.

En definitiva, pues, mientras para los entes públicos no económicos la misión de satisfacción directa e inmediata de los intereses públicos comportaría formas de organización y modalidades de gestión según específicos preceptos establecidos como garantía para la realización de aquellos intereses, en el caso de los entes públicos económicos, el interés público que preside a su institución se vería satisfecho en la medida en que fueran observadas las reglas que el ordenamiento prescribe para todos los empresarios. De ello se deriva, respecto de lo que a nosotros nos interesa, la aplicación de las reglas comunes del trabajo y la jurisdicción del juez ordinario.

\section{LOS PROBLEMAS CONSTITUCIONALES}

Durante mucho tiempo, gran parte de la doctrina, apoyada por la jurisprudencia de la Corte Constitucional, ha interpretado las previsiones de la Constitución republicana como una confirmación, o mejor, como una nueva legitimación de la peculiar naturaleza del empleo público como «relación de supremacía, atribuida en general a la Administración pública, en virtud de los objetivos propios de su función y con asignación a los empleados públicos de una actividad instrumental a tal fin» ${ }^{25}$. Esta interpre-

${ }^{23}$ Cfr. la Ley de 24 de febrero de 1941, núm. 254. Sobre sus vicisitudes cfr. A. CorpaCl, Riparto della giurisdizione e tutela del lavoro nella pubblica amministrazione, Milán, 1985, 91 y ss. y 135 y ss.

24 Cfr., entre otras, Cass., S. U., 2 de marzo de 1982, en Giur. It., 1982, I, 1, 615.

25 Corte Constitucional, 28 de julio de 1976, núm. 194, en Giur. Cost., 1976, 1207. 
tación fue la base para la adopción en 1956-1957 del nuevo estatuto de los empleados civiles del Estado, cuyos principios la jurisprudencia ha considerado aplicables, en defecto de específicas disposiciones, al empleo con los entes públicos no económicos distintos del Estado 26; y que, en consecuencia, ha terminado por constituir una especie de decálogo de principios generales comunes a todo el empleo público.

En esta normativa subyace la connotación pública de la relación, cuya regulación está reservada a la ley o, sobre la base de la ley, a la potestad reglamentaria de las Administraciones públicas y cuya gestión se realiza enteramente a través de actos administrativos (desde el procedimiento de incorporación del empleado a la Administración, pasando por los procedimientos de promoción, traslado, procedimiento disciplinario, hasta llegar a aquellos de resolución de la relación). Desde el punto de vista procesal todos ellos están sometidos a la jurisdicción del juez administrativo.

A decir verdad, la especialidad del empleo público entendida como necesaria sumisión, ya sea en cuanto a las fuentes de regulación ya sea en cuanto a los actos de gestión, a un régimen de Derecho público, no encuentra en la Constitución un explicito e inequívoco fundamento. Esta especialidad se extrae, más bien, relacionando una serie determinada de disposiciones constitucionales que se refieren a varios objetos: la organización administrativa, la función pública, además de distintas prescripciones dictadas para los empleados públicos.

Entre todas estas disposiciones destaca por su especial relieve el artículo 97, 1.c, que establece una reserva relativa de ley para la organización de los oficios públicos «de tal modo que sean asegurados el buen funcionamiento y la imparcialidad de la Administracións. De los principios de buen funcionamiento e imparcialidad se ha extraído la necesidad de la imprescindible connotación pública, ya sea de las fuentes de regulación de la organización de los oficios ya sea, más en general, de todo el conjunto de la actividad organizativa en la que se incluye también todo el aspecto relativo al personal ${ }^{27}$.

Justo refiriéndose al principio de buen funcionamiento, la Corte Constitucional ha afirmado en el pasado que «tal principio no se refiere exclusivamente a la organización de la Administración... (siendo) innegable que la regulación del trabajo es siempre

${ }^{26}$ Cfr. entre otros Cons. Stato, sez. IV, 22 de abril de 1980, núm. 411, en Cons. Stato, 1980, I, 491; ID, sez. VI, 14 de julio de 1982, núm. 366, ivi, 1982, I, 1004.

27 Cfr. P. Virga, Il pubblico impiego, Milán, 1973, 29-30; V. OTtavlano, «Poteri dell'amministrazione e principi costituzionalis, en Riv. Dir. Pubbl, 1964, 912. 
instrumental, directa o indirectamente, respecto a las finalidades institucionales asignadas a los oficios públicos en que se articula la Administración públicas ${ }^{28}$. Por lo que al principio de imparcialidad se refiere, su pertenencia al elemento personal de la organización administrativa se ve específicamente confirmada en otras previsiones constitucionales, en particular aquella que exige el concurso para la incorporación a los empleos públicos [97.3.c)] y aquella que prescribe condiciones de igualdad para el acceso a los oficios públicos [51.1. $\left.\left.{ }^{\circ} \mathrm{c}\right)\right]$; aquella que vincula a los empleados públicos «al servicio exclusivo de la Nación» [98.1. $\left.\left.{ }^{\circ} \mathrm{c}\right)\right]$; la que prescribe la determinación de las esferas de competencia, las atribuciones y la responsabilidad propia de los funcionarios $\left[\left(97.2 .^{\circ} \mathrm{c}\right)\right]$.

De ello se deduce que el constituyente habría situado el empleo público en el ámbito de la organización administrativa más que en el área del trabajo subordinado y, de todas formas, habría sancionado el carácter público y funcional de tal relación ${ }^{29}$. Incluso se ha observado ${ }^{30}$ que los artículos 97, 98 y 51 de la Constitución están inspirados en el modelo weimariano de la Administración neutral y que de tal modelo son igualmente partícipes ya sea la disciplina de la organización y de la función, ya sea la disciplina de la relación de empleo y de la prestación de trabajo, perfiles distintos pero inescindiblemente conexos.

Las tesis que hacen derivar del texto fundamental la necesidad de un régimen especial de carácter público del trabajo en las Administraciones públicas han sido objeto de distintas críticas. Estas críticas han adquirido tonos más radicales a partir de los años setenta por la intervención en el debate de expertos laboralistas. En especial, ha sido puesto en evidencia que junto a la materia examinada sobresalen en el plano constitucional, no sólo las disposiciones referentes a la organización administrativa y a la función pública, sino también los principios relativos al trabajo (arts. 35-40). Sólo el hecho de la falta de consideración de esta segunda serie de disposiciones pone en tela de juicio las anteriores conclusiones, que han sido alcanzadas teniendo en cuenta exclusivamente uno de los datos relevantes.

Volviendo a la cuestión del peso que hay que otorgar a una u otra serie de principios constitucionales, así como su armoni-

${ }^{28}$ Corte Costituzionale, 29 de abril de 1980, núm. 68, en Giur. Cost., 1980, 647; ID, 9 de diciembre de 1968, núm. 124, ivi, 1968, 2161.

${ }^{29}$ Así G. Paleologo, Principi di pubblico impiego, Milán, 1980.

30 Cfr. F. MERusi, «Vicende e problemi della contrattazione collettiva nell'impiego ospedalierow, en Atti del XXV convegno di studi di scienza dell'amministrazione su pubblico impiego e contrattazione collettiva, Milán, 1980, 42-44. 
zación, se ha resaltado que las garantías del trabajo tienen en la Constitución "por principio un carácter absoluto de conformación y tutela susceptible de alejar cualquier tipo de condicionamientos dependientes de la cualidad pública o privada del sujeto empleadon ${ }^{31}$. Cruzando tales consideraciones con aquella según la cual las normas constitucionales relativas a la organización de los oficios y a la función pública se refieren al empleo público sólo indirectamente e incidentalmente, se ha llegado a la conclusión de la prevalencia de los valores laborales: «los principios constitucionales sobre la prestación de trabajo en los entes públicos... deberán ser buscados ante todo, no en las disposiciones a las que se refieren los artículos $51,54,97$ y 98, sino más bien en aquellas contenidas en los artículos 35 y siguientes, que encontrarán aplicación a los dos sectores (privado y público) salvo las especialidades que las normas organizativas relativas a la Administración y a la función pública puedan de vez en cuando imponer o consentins ${ }^{32}$. En todo caso, la necesidad de armonizar los diversos valores emergentes de la Constitución ha inducido a negar un exclusivo dominio en esta materia del principio de legalidad y a considerar esencial la presencia de un espacio libre, dejado, no ya al señorío de la Administración, sino a la autorregulación negocial de las partes ${ }^{33}$.

Por otra parte, ha sido objeto de contestación la interpretación del artículo 97 de la Constitución y las conclusiones que, tal como se ha puesto de manifiesto, de ello se han derivado para fundamentar la necesidad del régimen público de empleo con las Administraciones públicas. De esta manera se ha sostenido que aquella norma debe entenderse referida, no ya a la organización administrativa genéricamente entendida, sino tan sólo a los oficios encargados del ejercicio de potestades públicas. Exclusivamente, pues, en este estrecho ámbito podría darse un vínculo de carácter público y se justificaría, en consecuencia, el carácter secundario e instrumental de los aspectos laborales respecto a la organización y al desarrollo de la función pública ${ }^{34}$. Más allá de este umbral no encontraría ningún fundamento la identificación de la actividad organizativa de la Administración pública y, en particular, del interés de ésta respecto a la relación de empleo público, con

31 G. BERT, «Impiego pubblico, contrattazione collettiva e tutela giurisdizionale», en Atti del XXV convegno di studi di scienza dell'amministrazione, cit., 268-269.

${ }^{32} \mathrm{G}$. CoRso, "Leggi comuni al rapporto di lavoro privato e all'impiego pubblicon, en Atti del XIX convegno di studi di scienza dellamministrazione, Milán, 1976, 159 y ss.

${ }^{33}$ G. MARongiu, "Vicende e problemi della contrattazione collettiva nell'impiego statale", en Atti del XXV convegno di studi di scienza dell'amministrazione, cit., 127 y ss., en particular 149-151.

34 M. Rusclano, L'impiego pubblico, cit., 372 y 339-340. 
el «interés general» o con un interés público en sentido propio: la Administración como empleadora uno procura ningún interés público, sino que procura su propio interés de tener un servicio personal, en orden al cual tiene, más concretamente, un interés instrumentals, ${ }^{35}$.

Las tesis mencionadas, aunque con argumentos y razonamientos distintos, coinciden en excluir que los principios constitucionales impongan una generalizada y absoluta configuración pública de la relación de empleo con las Administraciones públicas. A tal conclusión ha llegado también una doctrina que todavía considera inscrita en el texto fundamental una «noción constitucional de empleo público» ${ }^{36}$. En las previsiones antes mencionadas sobre el acceso a los oficios públicos por concurso y en condiciones de igualdad (que pretenden excluir posibles discriminaciones desde el momento mismo de acceso a la Administración y garantizar la presencia en la Administración de personas de distinto origen), sobre la determinación de las esferas de competencia de los funcionarios (que pretende separar funcionalmente la política de là administración), las previsiones sobre el servicio exclusivo a la Nación (que por un lado pretende tutelar a los empleados públicos de las injerencias indebidas de la politica $\mathrm{y}$, al mismo tiempo, asegurar que los empleados realizan sus funciones con el respeto debido a las determinaciones adoptadas en la forma constitucionalmente correcta por los órganos de dirección política) y, sobre todo, las previsiones sobre la responsabilidad directa de los funcionarios y empleados públicos por los daños causados a terceros (proclamada en el art. 28 en función de la exigencia de «instituir un control, en sentido técnico, sobre quien ejercita los poderes públicos y sobre la forma en que éstos son ejercitados») se percibe un intento de transposición a nivel de personal dependiente (de todo el personal dependiente) de los caracteres y de la forma de ser de la Administración en el ordenamiento democrático.

${ }^{35}$ M. S. Giannini, Impiego pubblico, cit., 303. Observa GianNini que desde el punto de vista estructural la actividad organizativa y de gestión del personal de las Administraciones públicas no es reconducible al ejercicio de potestades públicas, desde el momento en que cualquier sujeto juridico tiene la potestad de organizar su propia actividad y de dotarse de una otganización; ni siquiera lo es desde el punto de vista funcional puesto que en este caso la Administración no procura ningún interés público, sino un interés instrumental como cualquier otro sujeto juridico; en definitiva, pues, si es indudable que históricamente el régimen de Derecho administrativo ha respondido a la exigencia de un control público sobre la actividad en cuestión, también puede ser satisfecha tal exigencia mediante el recurso a una apropiada regulación de Derecho común. Sobre esta materia cfr. también M. Rusciano, L'impiego pubblico, cit., 336 y ss.

36 A. Cariola, La nozione costituzionale di pubblico impiego, Milán, 1991. 
Según esta lectura, la traducción a nivel de personal de los principios de imparcialidad y de buen funcionamiento $\mathrm{y}$, más en general, de los caracteres de la Administración según el modelo trazado en el texto fundamental, corresponde a una "personalización» de la Administración que apunta a la tutela y garantía de los derechos de los ciudadanos. La relevancia constitucional que de esta manera asume el empleo público justifica la especialidad de dicha relación, pero sin embargo, tal como antes hemos anticipado, no implica necesariamente, según la doctrina examinada, un régimen unilateral-público. En efecto, se considera que la exigencia de dar un apropiado y coherente desarrollo a las indicaciones constitucionales bien puede ser satisfecha por el legislador «a través de la imposición de normas imperativas, no derogables por la autonomía privada, según el esquema indicado por el segundo párrafo del artículo 1.419 del Código Civils ${ }^{37}$. Respecto a las leyes relativas al trabajo en dependencias privadas «en parte cambia la dirección de los intereses que las mismas normas satisfacen ya que, antes incluso de referirse a los empleados, pretenden asegurar la imparcialidad de la Administración... $y$, por otro lado, aparecen predispuestas a la tutela de los intereses públicos en la medida en que pertenecen a la entera comunidad social y, como tales, se imponen desde el exterior a la misma relación de trabajo» ${ }^{38}$.

El complejo marco constitucional relativo al empleo público ha sido más recientemente objeto de un atento análisis que ha llevado a algunas interesantes precisiones y distinciones conceptuales ${ }^{39}$. En particular, ha sido puesta de manifiesto la necesidad de distinguir y considerar separadamente tres órdenes de cuestiones relativas, respectivamente: a los contenidos materiales de la disciplina de la relación, a las fuentes de regulación del empleo público y, más en general, de la organización administrativa y al régimen jurídico de la relación de empleo público y de la actividad organizativa.

Se ha resaltado, en primer lugar, que las previsiones constitucionales que establecen preceptos sobre el contenido de la disciplina del empleo público (como, por ejemplo, la norma sobre el acceso a través de un concurso en condiciones de igualdad, o aquella sobre el servicio exclusivo a la Nación, entre otras) «no implican, en cuanto tales, ninguna conexión con el tipo de fuente habilitada para intervenir en su ámbito material de operativi-

37 A. Cariola, op. ait., 274.

38 A. Carjola, op. cit., 265.

39 A. OrSI BATAGLINI, «Fonti normative e regime giuridico del rapporto d'impiego con enti pubblicin, en Giom. Dir. Lav. Rel. Ind., 1992, 461 y ss. 
dad ${ }^{40}$. Tal aspecto es, en efecto, objeto de prescripciones ulteriores y añadidas que deben ser consideradas separadamente.

Respecto a estas últimas, y en particular a las numerosas reservas de ley que afectan a varios ámbitos materiales (organización de los oficios públicos, requisitos para el acceso, excepciones a las reglas del concurso, prohibición de inscripción en partidos políticos para determinadas categorías, entre otros) ha sido posteriormente apuntado que la necesidad constitucionalmente afirmada de una cobertura legislativa no implica «en modo alguno que, satisfecho este requisito, la restante área de regulación deba considerarse también reservada a fuentes unilaterales secundarias» ${ }^{41}$. Una rigurosa lectura del texto constitucional no permite afirmar una competencia reservada a las fuentes secundarias en materia de organización administrativa y de relación de empleo con entes públicos. En particular, una reserva de poder reglamentario no puede considerarse impuesta, ni siquiera por las prescripciones constitucionales sobre imparcialidad y buen funcionamiento. En efecto, más allá de las normas de contenido dictadas directamente por el legislador para la realización de tales objetivos, y de cara a la determinación de los instrumentos infralegales de regulación, parece «completamente arbitrario afirmar un indefectible nexo funcional entre la persecución de aquellos objetivos y la naturaleza unilateral y pública de las fuentes secundarias», pudiendo el buen funcionamiento y la imparcialidad ser alcanzados en la misma o mayor medida a través de su regulación contractual.

De esta argumentación se deriva que la elección de los instrumentos infralegales de regulación de la organización administrativa y de la relación de trabajo con los entes públicos debe dejarse en manos del legislador. Ello encuentra una concreta e histórica confirmación en la aplicación a la organización y al personal de los entes públicos económicos de un modelo inspirado en el régimen de Derecho privado, sin que se haya nunca dudado de su conformidad a la Constitución. Esta conclusión encuentra una ulterior puntualización y especificación a la luz de un examen comparativo de los principios constitucionales relativos a la organización administrativa y de aquellos relativos al trabajo. Desde el momento mismo en que la Constitución privilegia el principio laboral, debe deducirse la necesidad de que una amplia y significativa área se deje a su regulación contractual.

\footnotetext{
40 A. Orsi Bataglinl, op. cit., 462.

41 A. Orsi Bataglini, op. cit., 463.
} 
En cuanto al tercero de los aspectos antes mencionados, el relativo al régimen jurídico de la actividad de organización y de la relación de empleo, su instrumentalización para obtener la imparcialidad y el buen funcionamiento de la Administración, así como no requiere necesariamente una regulación infralegal de carácter público y unilateral, no implica tampoco el carácter inexcusablemente unilateral y público de la actividad organizativa y de la gestión de la relación de empleo. «El legislador dispone de un amplio margen de elección entre el régimen público y el régimen privado", constituyendo ambos modalidades distintas, pero a la vez idóneas, para cumplir las exigencias de imparcialidad y buen funcionamiento fijadas en el artículo 97 de la Constitación.

\section{EL PROCESO DE REVISIÓN LEGISLATTVA: LA LEY MARCO DE 1983}

La legislación de los últimos veinte años ha respondido, más que a las nuevas interpretaciones que parte de la doctrina venía realizando del cuadro constitucional, a las presiones provenientes del movimiento sindical para una profunda revisión del modelo tradicional. Respecto a ello puede decirse que, aunque hasta principios de los años sesenta el empleo público había sido objeto casi exclusivo de un sindicalismo de categoría fuertemente caracterizado por una visión corporativa y sectorial y centrado prevalentemente en los aspectos salariales, posteriormente, el reforzamiento de los sindicatos confederados ha abierto la vía para la puesta en discusión de la separación entre el trabajo público y privado, así como para la reivindicación de un mayor papel de las organizaciones sindicales, no sólo respecto al aspecto retributivo, sino también respecto a los aspectos de la organización del personal y de la organización del trabajo ${ }^{42}$.

Después de un primer período en que la participación de los sindicatos en el proceso de producción normativa se desarrolló informalmente, a partir de la mitad de los años setenta, una serie de leyes relativas a varios sectores de la Administración pública intervinieron para regular, aunque a través de distintas modalidades, el fenómeno de la negociación colectiva en el empleo público ${ }^{43}$. Finalmente, la Ley de 29 de marzo de 1983, núm. 93 (Ley marco sobre el empleo público) realizó esta primera fase

${ }^{42}$ Cfr. C. D’OrTA, $I l$ pubblico impiego, Roma, 1989, 17 y ss.

43 Véase L. Rainald, "Gli accordi sindacali nel pubblico impiego», en Riv. Trim. Dir. Pubbl., 19778,1419 y ss. 
de revisión del sistema al establecer una regulación unitaria de la negociación colectiva en cuanto al área de aplicación y a sus reglas de desarrollo y dando, en consecuencia, una nueva configuración al empleo público.

El área de aplicación de la Ley de 1983 abarca a todas las Administraciones estatales, incluso a las de ordenamiento autónomo, las regiones, provincias y municipios, asi como a los entes públicos no económicos nacionales, regionales y locales. En definitiva, pues, cubre todo el universo de los sujetos públicos, excluyendo únicamente a aquellos que se dedican exclusiva o prevalentemente a la actividad de empresa. En el ámbito de las Administraciones públicas no económicas permanecen fuera de la nueva disciplina, en razón de las funciones que ejercitan, específicas categorías (personal militar, de la carrera diplomática y de la policía del Estado, magistrados, abogados y procuradores del Estado, empleados de la Banca de Italia, dirigentes del Estado ${ }^{44}$ y de los entes paraestatales) para quienes permanece en vigor la anterior normativa.

En el área así individualizada la Ley marco introduce una serie de principios comunes que representan la base normativa de la nueva configuración del empleo público. Esta nueva configuración es fruto del reconocimiento del carácter autónomo del perfil laboral y, por tanto, de la superación de la idea según la cual la inserción del trabajo en la organización administrativa implicaría el absoluto dominio de las reglas y de los principios propios de esta última. Pero aunque este aspecto laboral asume un especial relieve, el legislador no llega a predicar una plena separación respecto a la organización administrativa. Se afirma un nuevo diseño que, por un lado, pretende distinguir todo lo que se refiere a los oficios y a la función de todo aquello que se refiere al trabajo, pero al mismo tiempo quiere mantener un vínculo entre ambos aspectos; un diseño que surge con particular evidencia en la sistematización dada a las fuentes de producción normativa de esta materia.

Junto a la tradicional fuente legislativa o reglamentaria de carácter unilateral (a la que permanece reservada la disciplina de la organización de los oficios, así como aquellas instituciones de la relación de empleo que más se reflejan en la organización de los oficios y de las funciones ${ }^{45}$ ) se establece, para los aspectos más

44 Ante la inexistencia de una categoría equivalente en nuestro ordenamiento juridico, es preciso advertir que utilizaremos el término «dirigente» para referimos a aquella categoría de empleados públicos italianos, I dirigenti, formada por profesionales encargados de dirigir las Administraciones públicas bajo la dirección y control del Gobierno.

${ }^{45}$ El artículo 2 de la Ley núm. 93 de 1983 reservaba explíciamente a la ley: 1) los órganos, 
inmediatamente relacionados con la organización del trabajo, un mecanismo de producción normativa basado en los acuerdos con las organizaciones sindicales representativas de los empleados. Desde varios puntos de vista puede decirse que se trata de una solución de compromiso.

En primer lugar, porque la distinción entre las dos modalidades de fuentes no se refiere a la distinción entre organización administrativa y organización del trabajo: tal como se ha señalado anteriormente, una serie de aspectos referentes a esta última (entre los cuales basta recordar los procedimientos de constitución, modificación y extinción de la relación; los criterios para el establecimiento de la categoría profesional; la responsabilidad disciplinaria) continúan todavía sujetos a las fuentes unilaterales.

En segundo lugar, porque la fuente que se encarga de la regulación de las materias sometidas a la negociación con las organizaciones sindicales no es en realidad una verdadera y propia fuente negociadora. Efectivamente, el acuerdo entre la delegación de la parte pública y las organizaciones sindicales aparece insertado en el ámbito de un procedimiento escrupulosamente regulado por la ley y que concluye mediante un decreto del Presidente de la República (un reglamento) a través del cual «son recibidas y emanadas al mismo tiempo las normas resultantes del acuerdo" ${ }^{46}$. Tal como ha sido resaltado ${ }^{47}$, el convenio colectivo, debido a su inserción en un procedimiento administrativo destinado a concluirse como si se tratara de un reglamento, acaba revistiendo «el carácter, completamente desconocido al Derecho privado, de requisito indispensable para la legitimidad de los actos que regulan la relación. El modelo privado no contempla el convenio colectivo necesario ni la obligación de contratan.

Por otra parte, la Ley marco no pone en discusión la naturaleza pública de la relación de empleo. También sobre este aspecto, aunque introduce algunos principios normativos que proyectan la relación en una dimensión laboral ${ }^{48}$, aunque extiende

los oficios y los principios fundamentales de organización de los mismos; 2) los procedimientos de constitución, modificación y extinción de la relación de empleo; 3) los criterios para la determinación de las categorias funcionales y de los aspectos profesionales; 4) los criterios para la formación profesional y de adiestramiento; 5) las funciones de los órganos; 6) las garantías del personal para el ejercicio de la libertad y de los derechos fundamentales; 7 responsabilidad de los empleados, incluida la responsabilidad disciplinaria; 8) la duración máxima del horario del trabajo; 9) ejercicio de los derechos de los ciudadanos en sus relaciones con los empleados públicos.

${ }^{46}$ Cfr. el articulo 6 de la Ley núm. 93.

47 Véase al respecto a T. TREU, «La contrattazione collettiva nel pubblico impiego», en Gior. Dir. Lav. Rel. Ind., 1994, 1 y ss.

48 Por su particular importancia, la introducción del sistema de clasificación por categorias funcionales (art. 17), que implicaba la clasificación del personal en base a la urcagrupación homogénea de las actividades laborales). 
o pone las premisas para extender a los empleados de las Administraciones públicas la tutela sindical dictada para el sector privado por el Estatuto de los Trabajadores ${ }^{49}$, aunque con la formal implicación de los sindicatos en el proceso de producción normativa abre el camino para un acercamiento y una ósmosis entre la disciplina del sector público y la del sector privado, mantiene, sin embargo, como estable e indiscutible aquella diferenciación de fondo consistente en la reconducción del empleo con las Administraciones públicas al Derecho administrativo y en el sometimiento de las controversias al juez administrativo.

En relación con este último aspecto, la norma sobre la tutela jurisdiccional es extremadamente significativa de la solución de compromiso adoptada por el legislador: confirma la jurisdicción del juez administrativo pero, al mismo tiempo y precisamente en consideración a la importancia y al peso reconocido al aspecto laboral, establece que uen sede de revisión de la jurisdicción administrativa se procederá a la elaboración de normas que se inspiren, para la tutela jurisdiccional del empleo público, en los principios contenidos en la normativa sobre el proceso laboral ante el juez ordinario y en el Estatuto de los Trabajadores» ${ }^{50}$.

En definitiva, pues, la originalidad de la Ley marco ha consistido en el reconocimiento de un autónomo relieve al aspecto laboral de la relación, aun manteniendo las formas jurídicas públicas, $y$, sobre todo, en apuntar a una adaptación de éstas para hacerlas coherentes con aquel aspecto. Tal adaptación, llevada a cabo en materia de fuentes de regulación en la manera en que antes se ha dicho, es, por lo demás, reenviada a una futura intervención del legislador (en cuanto a la tutela jurisdiccional), o bien dejada a la propia dinámica de las relaciones sindicales y a la labor de la jurisprudencia (en cuanto a las reglas y a la configuración de la relación de empleo).

Pero por diversas razones este nuevo diseño no ha tenido éxito.

El legislador no ha sido fiel a la obligación de realizar una regulación procesal que, manteniendo la jurisdicción del juez administrativo, estuviera inspirada en la disciplina del proceso laboral ordinario. De manera que sobre este plano ha faltado la superación del tradicional modelo que ponía en el centro el poder público de organización de la Administración pública $\mathrm{y}$, configu-

49 El título III de la Ley núm. 93, dedicado a la tutela sindical del empleo público, preveía una directa extensión de algunas normas del Estatuto de los Trabajadores, mientras que para otras enviaba a una futura regulación que debería dictarse en base a acuerdos con los sindicatos y la aplicación de los principios en aquélla contenidos.

50 Artículo 28 de la Ley núm. 93 cir. 
rando la tutela del empleado como mera emanación del legítimo ejercicio del primero, lo ligaba a las técnicas de control sobre el ejercicio de tal poder. En defecto de una intervención orgánica del legislador ha sido la Corte Constitucional quien ha debido hacerse cargo del problema a través de dos sentencias ${ }^{51}$ de 1985 y de 1987 que, refiriéndose a la tutela cautelar y a los medios instructorios, han sancionado la inadecuación de los instrumentos procesales aplicados a las controversias del empleo público. Sin embargo, han aportado un remedio que ha permanecido marginal y episódico básicamente en razón del sólido apego del juez administrativo a las usuales modalidades del control sobre el ejercicio del poder administrativo.

Llegamos, así, al segundo de los aspectos, el relativo a la adaptación que habría debido investir la estructura y la configuración de la relación. Si bien, y tal como hemos dicho, la Ley marco no rompía los nexos entre organización administrativa y relación de empleo ni ponía en discusión la naturaleza pública de este último, abandonaba, sin embargo, la dislocación con el mundo del trabajo, reservando precisamente por ello un ámbito de la disciplina a la negociación con las organizaciones sindicales. Todo ello debería haberse reflejado en la configuración de la relación y, en particular, debería haber conducido a una revisión sobre la forma de concebir la posición de la Administración en esta materia.

Según la configuración tradicional, el carácter autoritario de los actos de gestión del empleo corre paralelo al carácter unilateral de las fuentes de regulación; uno y otro son consecuencia del postulado según el cual la materia de empleo se sitúa en el ámbito del poder organizativo de la Administración pública y, gobernada por tal poder, está sujeta a las reglas y a los principios que le afectan. Pero desde el momento mismo en que tal postulado es en parte superado, y desde el momento en que una serie determinada de instituciones y aspectos de la relación son some-

51 Cfr., por un lado, Corte Cost., 28 junio de 1985, núm. 190, en Foro Amm., 1986, 1, con la que ha sido declarado inconstitucional el último párrafo del artículo 21 de la Ley núm. 1034 de 1971, creadora de los TAR, uen la medida en que, limitando la intervención de urgencia del juez administrativo para la suspensión de la ejecutividad del acto impugnado, no permitia al juez mismo adoptar en las controversias patrimoniales en materia de empleo público... los procedimientos de urgencia que considerara oportunos según las circunstancias más idóneas para asegurar provisionalmente los efectos de la decisión sobre el fondom; $y$, por otro lado, Corte Cost., 23 de abril de 1987, núm. 146, en For Amm., 1987, 1341 (con comentario de G. VACIRCA, "Prime riflessioni sul nuovo regime dalle prove nelle controversia in materia di pubblico impiegom), a través de la cual han sido declaradas inconstitucionales una serie de normas relativas a los medios de instrucción en el proceso administrativo, en la medida en que eran considerados perjudiciales para la tutela en juicio de los empleados públicos. 
tidos a una fuente de regulación que es fruto de la confrontación paritaria entre Administración y representantes sindicales de los empleados, las determinaciones relativas a cada una de las relaciones deberían, en igual medida, haber sido reconducidas a la común actividad de organización y gestión del trabajo más que a la especial actividad de ejercicio de poder administrativo. Correlativamente, las situaciones de las partes deberían haber sido configuradas en términos de recíprocos derechos-obligaciones más que en términos de potestad-interés legítimo.

Por el contrario, puede decirse que ha faltado casi por completo un desarrollo en tal sentido, tal como se desprende del reducido número de casos en que el juez administrativo ha logrado calificar como detecho subjetivo la situación jurídica del empleado. En la mayoría de los casos el juez administrativo ha continuado reconduciendo la actividad de la Administración al ejercicio de la potestad administrativa y configurando la acción en el juicio como un medio de impugnación introductorio de un juicio sobre la legitimidad de un acto, en vez de un medio de verificación de una determinada situación jurídica. De manera análoga, la aplicación de las normas comunes del trabajo ha sido admitida en los limites de una rigurosa compatibilidad respecto a la predicada especialidad del empleo público.

Basta recordar a modo meramente ejemplificativo la constante jurisprudencia que ha reducido el principio de la justa retribución, contemplado en el artículo 36 de la Constitución, a criterio de valoración de la legitimidad de los actos adoptados por la Administración, de tal manera que, en defecto de impugnación de tales actos en el plazo establecido para ello, no es posible invocar la aplicación del principio constitucional ${ }^{52}$. $\mathrm{O}$, incluso, la afirmación según la cual la compensación por el trabajo extraordinario prestado por el empleado público no puede ser reconocida cuando falte la previa y formal autorización de la Administración, considerando el juez que sólo sobre la base del formal acto de autorización es posible verificar la real subsistencia de las razones de interés público que justifican la prestación de trabajo extraordinario ${ }^{53}$.

Por otra parte, la propia innovación introducida por la Ley marco sobre las fuentes de regulación del empleo ha revelado múltiples defectos. Sobre todo, y tal como se ha anticipado, la distinción entre fuentes unilaterales y fuentes negociadoras no

52 Cfr., por ejemplo, Cons. Stato, sez. V, 14 de enero de 1991, núm. 30, en Foro Amm. $1991,42$.

${ }_{53}$ Cfr. Cons. Stato, sez. V, 13 de septiembre de 1991, núm. 1154, en Foro Amm., 1991, 2269. 
responde a una clara y neta separación entre ámbitos distintos ${ }^{54}$, en particular entre materias relativas a la organización y materias relativas a la relación de trabajo. Estaba reservada a la ley, no sólo todo lo referente a la organización administrativa, sino también la regulación de no pocos aspectos de la relación de empleo. Para determinadas materias, asimismo, correspondía también a la ley la definición de los "principios fundamentales» y de los «criterios», estableciéndose de esta forma la posibilidad de una intervención concurrente, si bien graduada, de las dos fuentes.

El reparto, por tanto, resultaba incierto, no sólo por la dificultad que entrañaba la determinación de la línea que marcaba la frontera y de la ratio en que se basaba, sino también por la falta del establecimiento explícito de un criterio que sirviera para resolver los problemas que planteaban determinadas materias $o$ institutos no atribuidos expresamente o situados a caballo entre la competencia de una $u$ otra fuente.

Además de todo ello, el área de competencia de las dos fuentes, en particular de las fuentes negociadoras, al ser definida en una ley ordinaria ha resultado totalmente disponible respecto a leyes sucesivas que, al estar dotadas de igual fuerza que la Ley marco, no podían considerarse vinculadas por ella. De hecho, las incursiones legislativas en las materias sometidas a las fuentes negociadoras han sido numerosas, agravando la inestabilidad y la precariedad del modelo ${ }^{55}$.

Pero, por otra parte, se ha producido también un fenómeno de signo contrario, de intrusión de las fuentes negociadoras en el área reservada a la regulación legal. En teoría, distinto de cuanto apenas acabamos de decir para la ley, la fuente negociadora, asumiendo forma de reglamento, deberia haberse sujetado a los límites establecidos en cuanto a su propia competencia. En la práctica, sin embargo, la línea de separación de los confines no ha permanecido incólume a la presión de las organizaciones sindicales para la extensión del ámbito de la negociación ${ }^{56}$. Ello no sólo se ha producido a causa de la incerteza en la definición

${ }^{54}$ Cfr. M. Rusciano, «Commento agli artt. 2 e 3 della legge 29 marzo 1983, núm. 93», en Le nuove leggi civili commentate, 1984, 605 y ss.

${ }_{55}$ Cfr. L. FioriLlo, (Dentro e fuori della legge quadro: chi disciplina l'impiego pubblicos), en Lav. Dir., 1989, 541 y ss.

${ }^{56} \mathrm{La}$ extensión de la negociación ha sido mantenida por la previsión en los así llamados convenios nacionales y descentralizados de derechos de intervención de los sindicatos en determinados aspectos de la regulación y gestión de la relación de empleo. A ello se han añadido otras formas de participación sindical consistentes en la presencia de representantes en organismos de gestión de la telación (consejos de administración, comisiones de disciplina, comisiones de concursos, etc.). Ha surgido así un sistema de dificil cogestión. 
de tal línea separadora, que para algunos aspectos se había redactado de forma abstracta, por no decir indescifrable, sino también, y en mayor medida, por la extrema dificultad que suponía conciliar el reconocimiento de un relieve propio al aspecto laboral, y en consecuencia de un papel a la negociación sindical, con la sustracción al mismo tiempo de determinadas materias e institutos pertenecientes a la organización y gestión del trabajo.

Uno de los puntos de mayor debilidad de la Ley marco está en no haber fundamentado la distinción entre fuentes unilaterales y fuentes negociadoras en un criterio racional y (relativamente) preciso, como habria podido ser el confiar a la primera todo aquello que se refiriera a la organización administrativa y a la segunda todo lo relativo al trabajo. En su defecto, se ha producido una situación de confusa concurrencia y superposición entre las dos fuentes.

Por otro lado, también por lo que se refiere a las modalidades de negociación en el sector público, la solución de compromiso adoptada por la Ley de 1983 ha resultado ser insatisfactoria. En efecto, no se ha llegado a admitir la estipulación de verdaderos y auténticos convenios colectivos, sino que se ha optado por una construcción híbrida que incorporaba la actividad negociadora en una maraña de reglas y de pasos procedimentales hasta conducir finalmente a la adopción de un acto que reviste la forma de reglamento.

Se habia establecido, ante todo, que la negociación debería realizarse por compartimientos ${ }^{57}$ (sectores homogéneos y afines), determinados en su número y en su composición mediante decretos del Presidente de la República, previa deliberación del Consejo de Ministros adoptada previa propuesta del Presidente del Consejo y sobre la base de los acuerdos alcanzados con las confederaciones sindicales más representativas a nivel nacional. Estaba minuciosamente regulada la composición de las delegaciones de la parte pública y de la parte sindical legitimada para negociar en cada compartimiento.

Se preveía que la propuesta de acuerdo formulada por las delegaciones negociadoras fuera sometida al Consejo de Ministros quien, una vez verificada la compatibilidad financiera y examinadas eventuales observaciones transmitidas por las organizaciones sindicales disidentes, autorizaba la suscripción.

${ }^{57}$ Hemos preferido utilizar la traducción exacta y literal del término empleado por la reforma italiana comparti para referirnos a los sectores en que ha sido dividida la Administración pública a efectos de la negociación colectiva. 
Suscrito el acuerdo, la regulación contenida en el mismo debía adoptar la forma de decreto del Presidente de la República, previa deliberación del Consejo de Ministros. Sobre dicho acuerdo existía un control de legitimidad de la Corte de Cuentas y, hasta 1990, era también solicitado un dictamen del Consejo de Estado.

Tal como se ha dejado entrever, la negociación estaba constreñida, por un lado, a los límites de las materias que le eran atribuidas por la ley y, por otro lado, estaba reducida a módulo interno de un procedimiento público, vinculada a predeterminadas modalidades organizativas y privada de la capacidad para producir efectos directos e inmediatos. En definitiva, pues, estaba revestida de un traje ampliamente inadaptado a un fenómeno que, de otro modo, sería expresión de una autonomía constitucionalmente garantizada como posición de libertad (art. 39 de la Constitución), en cuanto tal, por su naturaleza refractaria a imposiciones dirigidas y funcionales.

\section{LA REFORMA DE 1992-1993. UNA ADVERTENCIA PREVIA}

Las carencias y la ambigüedad del modelo diseñado por la Ley marco, que emergen con particular agudeza en su aplicación práctica, son la causa de la reforma llevada a cabo en 1992. Junto a los aspectos antes señalados, existen además otros de no menor importancia que han inducido al legislador a superar aquel modelo.

Principalmente un problema de contención del gasto. También para este aspecto la experiencia de la Ley marco resultó fallida. Ello, no sólo por la falta de idoneidad de los mecanismos técnicos que habrían debido consentir el control del gasto, sino también a causa de las modalidades de negociación, puesto que como representantes de la parte pública se habían previsto delegaciones compuestas por personal político. Como resultado de ello se llegó a una práctica negocial distorsionada, completamente inspirada en la búsqueda del consenso político, hasta convertirse en "protagonistas de fondo electoral-clientelan» ${ }^{58}$. La parte empresarial - por denominarla de alguna manera- se ha mostrado a veces dispuesta a conceder más de cuanto solicitaban los sectores responsables de las organizaciones sindicales; además de ello, su connotación estrechamente política ha descuidado los

58 U. ROMAGNOL, «La revisione del pubblico impiego: dal disastro verso l'ignoto", en $L a v$. Dir., $1993,231$. 
objetivos de eficiencia y productividad, perpetuando una perversa relación de intercambio entre baja eficiencia, seguridad del trabajo y. salarios bajos.

Otro no menos importante motivo de sufrimiento se producía por el mal funcionamiento de las Administraciones públicas, en parte debido seguramente a una débil y mala organización y gestión de los recursos humanos. Sobre este aspecto se hacía necesario insistir en dos cuestiones: la de la definición de un más claro y significativo papel de la clase directiva, para la que se solicitaba una ampliación de sus poderes de gestión y una mayor autonomia y responsabilidad en cuanto a su ejercicio; y la de los instrumentos jurídicos aplicables a la organización y gestión del trabajo.

En cuanto a esta última cuestión, el empujón dado hacia las reglas "comunes» del trabajo privado ${ }^{59}$ se apoyaba también en las denuncias sobre la disfuncionalidad de los instrumentos del Derecho público. Estaba ligado al régimen del acto administrativo y a las modalidades de tutela jurisdiccional del juez administrativo una rigidez derivada del exceso de vínculos y garantias, de la atribución de un papel prevalente, por no decir exclusivo, al canon de la legalidad en detrimento de la eficacia y de la eficiencia $y$, en suma, de la mayor atención respecto a las formas y a las reglas procedimentales que a los objetivos a conseguir.

Con la intención de dar solución a todas estas cuestiones apenas señaladas, el artículo 2 de la Ley de 23 de octubre de 1992, núm. 421, delegó en el Gobierno la realización de una profunda revisión de la disciplina en materia de empleo público y organización administrativa. En actuación de la delegación, el Decreto Legislativo de 3 de febrero de 1993, núm. 29, ha establecido múltiples novedades en materia de regulación del trabajo en las Administraciones públicas: basta citar el sistema de relaciones entre función de dirección política-administrativa y las tareas de gestión y, paralelamente, entre los órganos de gobierno y la clase directiva; la regulación de las funciones directivas ${ }^{60}$ y del acceso a dicha clase; la actividad de la Escuela

59 Cfr. M. Rusciano, «Rapporto di lavoro "pubblico" e "privato": verso regole comuni?), en Lav. Dir., 1989, 371 y ss., quien fija en la realización de un único sistema de relaciones de trabajo, centrado en un único tipo contractual (el contrato de trabajo subordinado), el objetivo a perseguir. Rusciano subraya que la estructura elemental del contrato de trabajo -al contrario de lo que ocurre en la relación de empleo público en su configuración tradicional- está provista de la ductilidad necesaria para garantizar una ágil y eficaz utilización de la fuerza del trabajo tanto en la empresa como en las Administraciones públicas.

${ }^{60}$ Es éste un aspecto particularmente importante y conectado con las innovaciones referentes a la relación de empleo en el momento en que es asignado a la clase directiva un papel esencial en materia de organización y gestión del trabajo, así como en las relaciones 
Superior de la Administración Pública; el sistema de controles, etc. En esta sede no es posible afrontar, ni siquiera superficialmente, todos estos aspectos, por lo que nos limitaremos a aquellos que más inmediata y directamente se refieren a la materia de empleo público. En primer lugar serán expuestas las ventajas de la nueva regulación. Posteriormente nos centraremos en algunos aspectos problemáticos $y$, sobre todo, en la cuestión de la coherencia de la privatización con el marco constitucional.

Con carácter preliminar es preciso hacer una advertencia previa.

Hasta hoy es prematuro hablar de un nuevo modelo de trabajo público; es más correcto, o mejor dicho, más real, hablar de un proceso hacia un nuevo modelo. En efecto, la reforma se caracteriza por su proyección y su carácter gradual. La Ley núm. 421 de 1992 y el Decreto Legislativo núm. 29 de 1993 han trazado objetivos y líneas clave, han definido los instrumentos para su realización y han realizado algunos cambios importantes, entre los cuales destaca la sustracción de la relación de empleo al régimen de Derecho público. Frente a esta fundamental mutación en cuanto a la naturaleza jurídica de la relación, inmediatamente operativa, el cambio en otros aspectos, o bien está en curso de realización o bien está todavía por producirse.

En relación con los contenidos materiales de la disciplina de la relación de trabajo, el carácter gradual de la reforma ha encontrado expresión en el establecimiento de una fase transitoria durante la cual permanece en vigor la normativa anterior, salvo su sustitución a través de los convenios colectivos y teniendo en cuenta la previsión según la cual desde el momento de la suscripción del segundo convenio colectivo «las disposiciones vigentes dejan en todo caso de producir efectos» ${ }^{61}$. De esta manera corresponde a los nuevos convenios colectivos hacer efectiva una transformación que de otro modo se vería limitada a una mera enunciación de principios. La calidad y la medida de tal transformación depende sensiblemente de las concretas modalidades que asuma la negociación y de la revisión que se produzca de la antigua disciplina.

Los convenios estipulados en la primera ronda tras la reforma ${ }^{62}$ han realizado una nueva regulación de algunas (pocos, no

sindicales. Sobre este aspecto nos remitimos a C. D'OrTA-C. MeOLi, La riforma della dirigenza pubblica, Padua, 1994, en especial a las páginas 85 y ss.

${ }^{61}$ Cfr. el artículo 72 del Decreto Legislativo núm. 29.

62 Para un examen de las soluciones adoptadas por los primeros convenios colectivos del nuevo curso (ministerio, entes paracstatales, tegiones y entes locales, sanidad y escuela) en comparación con la disciplina contractual de algunos sectores de servicios y de la industria, 
obstante) seleccionadas instituciones, entre las que destacan las sanciones y el procedimiento disciplinario. Por la terminología y la técnica utilizada, el distanciamiento con el modelo público y su acercamiento con el privado es absolutamente evidente. Sin embargo, deja vislumbrar también cierta continuidad. En su conjunto emerge un panorama variado en el que sólo en parte el nuevo modelo sustituye al antiguo y respecto al que todavía queda mucho por hacer.

Por lo que respecta al aspecto de la tutela jurisdiccional, el traspaso de la jurisdicción del juez administrativo al juez ordinario del trabajo - aspecto. crucial de la reforma - ha sido reenviado a una fecha futura. La permanencia transitoria del juez administrativo, desde el momento mismo en que éste continúa actuando como si nada hubiera cambiado, quita posibilidades a la reforma. Ciertamente, la orientación del juez no constituye para las Administraciones un estímulo a seguir en la nueva época, sino que más bien representa un importante soporte para una actuación de espera pasiva y de perpetuación de viejas prácticas.

En definitiva, pues, el alcance real, la efectividad y los éxitos del cambio permanecen todavía ampliamente indefinidos.

\section{LA PRIVATIZACIÓN-CONTRACTUALIZACIÓN DEL EMPLEO CON LAS ADMINISTRACIONES PÚBLICAS}

El eje central de la reforma del 92-93 es la reconducción de las relaciones de trabajo de los empleados de las Administraciones públicas bajo la disciplina del Código Civil y del Derecho común del trabajo, buscando al mismo tiempo garantizar adecuadamente «los intereses generales a cuya satisfacción está dirigida la organización y la actuación administrativa» ${ }^{63}$. En particular, se establece que las relaciones de trabajo con las Administraciones públicas «son reguladas contractualmente» y que «en las materias sujetas a la disciplina del Código Civil, a las leyes sobre el trabajo y a los convenios colectivos... (las Administraciones Públicas) actúan con los poderes del empresario privado" ${ }^{64}$.

La privatización-contractualización se refiere a todas las Administraciones públicas de carácter no económico (Estado, Regiones, entes locales territoriales, entes públicos nacionales y

nos remitimos a la obra dirigida por L. ZOPPOL,, Contratti collettivi a confronto: impiego pubblico, industria, senvizi, Milán, 1996.

63 Asi, el artículo 2, c.2, del Decreto Legislativo núm. 29.

64 Así, respectivamente, los artículos 2, c.3, y 4, c.1, del Decreto Legislativo núm. 29. 
locales), con excepción de algunas categorías de personal que, grosso modo, coinciden con las que en el año 1983 fueron excluidas de la aplicación de la Ley marco, pero con una pequeña variación relativa a la clase directiva. En las Administraciones estatales, y en aquellas otras donde ello esté contemplado en "específicas disposiciones de leyes estatales», la clase directiva está articulada en dos categorías: "directivos generales» y "directivos»; para el resto (lo que es aplicable para la generalidad de las Administraciones y, entre éstas, para las Regiones y entes locales) está prevista una categoría única de "directivo» ${ }^{65}$. Frente a ello, la relación de empleo es mantenida en régimen de Derecho público sólo para la más restringida franja de los directivos generales, mientras que ha sido privatizado-contractualizado para los demás directivos.

Por lo que al objeto se refiere, la privatización-contractualización encuentra un límite importante por el mantenimiento en un régimen de Derecho público de determinadas materias específicamente enumeradas ${ }^{66}$. Las expresiones usadas por el legislador en la determinación de las materias excluidas de la contractualización no brillan por su claridad y han provocado interpretaciones inciertas. Dejando a salvo determinados márgenes de interpretación motivados por las no perspicaces definiciones legales, la lectura más coherente con la ratio inspiradora de la reforma induce a pensar que la disciplina pública permanece para todo lo que se refiere a la organización administrativa $y$, por añadidura, para un número limitado de instituciones pertenecientes al trabajo; en particular, los procedimientos de selección para el acceso y la disciplina de la incompatibilidad en la acumulación de empleos públicos y otras actividades o cargos. Dejando al margen estas excepciones, todas las demás materias o instituciones referentes a la relación de trabajo se incluyen, pues, dentro del área privatizada-contractualizada ${ }^{67}$.

En consonancia con ello, la negociación colectiva abandona su apariencia de fase interna de un procedimiento destinado a concluirse con una resolución normativa que recoge los contenidos del acuerdo y asume su natural identidad de fuente negociadora que produce efectos inmediatos y directos según el Derecho privado ${ }^{68}$.

\footnotetext{
65 Artículo 15, c.1, del Decreto Legislativo núm. 29.

66 Cfr. el artículo 2, c.1, letra c, núm. del 1 al 7, de la Ley de 23 de octubre de 1992,

67 Cfr. M. BARBIERI-M. G. Garofalo, «La contrattazione collettiva", en Il lavoro alle dipendenze dalle amministrapioni pubblicbe. Comentario dirigido por F. CARINCI, Tomo I, Milán, 1995, 755-758.

68 Cfr. T. TREU, La contrattapione collettiva, cit.
} núm. 421. 
El cambio operado respecto de la Ley marco es radical: en el anterior sistema la negociación colectiva constituía un paso necesario para la formación de una fuente de producción normativa simétrica a la fuente legislativa y llamada a concurrir necesariamente con esta última en la regulación del empleo sobre la base de una previa atribución de competencia para determinadas materias. En el nuevo sistema la negociación colectiva es libre y autosuficiente aunque también dentro de los limites establecidos por la ley. Límites que se refieren, ya sea a los objetos (exclusión de las materias que permanecen en un régimen de Derecho público), ya sea a los contenidos de la regulación (por vía de los vínculos que derivan del convenio por la disciplina de la fuente legislativa $y$, en particular, por las normas inderogables por ésta establecidas), ya sea al procedimiento negociador. La sujeción a estos límites y vínculos no contradice, sin embargo, la libertad de negociación colectiva ${ }^{69}$. Incluso permitiendo la aplicación de los principios y de los instrumentos del Derecho común, pretende, más bien, salvaguardar las peculiaridades innatas a la naturaleza pública del sujeto empleador y satisfacer las correspondientes exigencias organizativas y funcionales.

Por lo que a la negociación colectiva específicamente se refiere, las normas reformadoras no concretan los niveles (nacional o descentralizado) ni los respectivos ámbitos, pero sí establecen una articulación de la negociación nacional en compartimientos que comprenden sectores homogéneos o afines ${ }^{70}$; regulan la representación negocial de las Administraciones públicas y disciplinan el procedimiento para la formación del convenio.

En cuanto a los niveles de negociación el sistema refleja una clara relación jerárquica entre negociación nacional y negociación descentralizada. En efecto, esta última puede desarrollarse sobre

${ }^{69}$ Cfr. M. D'ANTonA, «La neolingua del pubblico impiego riformatom, en Lav. Dir., 1996, 243.

70 Está prevista una eventual estipulación de convenios colectivos marco a través de los cuales se disciplinaria, de manera uniforme para todos los compartimientos, especificas materias (art. 45, c.5, del Decreto Legislativo núm. 29). La determinación de los compartimientos está confiada a un procedimiento negociador que recalca el viejo modelo propio de la Ley núm. 93 de 1983: efectivamente, requiere la elaboración de un decreto del Presidente del Consejo de Ministros en base a los acuerdos estipulados entre la Agencia para la Representación Negocial de las Administraciones públicas y las confederaciones sindicales más representativas a nivel nacional [art. 45.c).2, del Decreto Legislativo núm. 29]. Ello ha suscitado fuertes críticas, no sólo por el hecho de que su cumplimiento haya sido dejado en manos de un procedimiento (recepción del acuerdo en un acto de naturaleza pública) completamente espurio respecto al nuevo modelo de negociación. La heterodeterminación de las unidades negociadoras es considerada, en cuanto tal, comprensiva de la autonomia colectiva y, por tanto, se denuncia su contraste con el artículo $39,10^{\circ} \mathrm{C}$ de la Constitución, que excluye limitaciones a la libertad y a la autonomía sindical en materia organizativa. Sobre este punto cfr. M. BArblerl-M. G. Garofalo, La contrattazione collettiva, cit., 698 y ss. 
las materias y dentro de los limites determinados por los convenios nacionales; no puede comportar obligaciones de gasto que excedan de las posibilidades financieras definidas por la misma negociación nacional ${ }^{71}$. En definitiva, pues, la descentralización negociadora asume un claro carácter derivado y jerárquicamente predeterminado ${ }^{72}$.

Centrándonos en materia de representación negocial, es preciso señalar que ésta viene obligatoriamente atribuida a una específica Agencia ${ }^{73}$ creada para la negociación colectiva a nivel nacional por cuenta de todas las Administraciones públicas ${ }^{74}$. Para la composición del comité directivo de la Agencia son llamados cinco «expertos de reconocida competencia en materia de relaciones sindicales y de gestión del personaly, con exclusión de aquellos que ocupen cargos públicos electivos o cargos en partidos políticos o en sindicatos, así como aquellos que hayan tenido en el bienio precedente cargos directivos o relaciones de colaboración o de consulta con carácter continuo con las antedichas organizaciones. Las distintas delegaciones «politizadas y precarias» ${ }^{75}$ previstas en la Ley marco son así sustituidas por una estructura estable, con una clara connotación técnica y en la que se concentra toda la actividad de negociación a nivel nacional para todos los compartimientos.

El carácter público del procedimiento para la estipulación del Convenio ${ }^{76}$ se manifiesta en las directivas que el Presidente del Consejo 77 imparte a la Agencia, través de las cuales son indicadas

71 Cfr. los artículos 45 , c.4 y 51, c.3 del Decreto Legislativo núm. 29.

72 Cfr. A. Viscomi-L. ZoppoL, «La contrattazione decentrata», en Il Lavon alle dipendenze delle amministrazioni, cit., 790 y ss.; M. BARBIER-M. G. GAROFALO, La contrattazione collettiva, cit., 710-714.

73 Para un examen más exhaustivo de esta materia nos remitimos a A. CoRPAC, «Agenzi per la Rappresentanza Negoziale e autonomia delle pubblique amministrazioni nella regolazione dalle condizioni di lavoro", en Le Regioni, 1994, 1025 y ss.; L. GaETA-P. PASCuCCI, eL'Agenzia per la Rappresentanza Negoziale, en L'impiego pubblico nel diritto del lavoro, dirigido por $\mathrm{M}$. Rusclano y L. Zoppoli, Turín, 1993, 257 y ss.

${ }^{74} \mathrm{El}$ artículo 50, c.7, del Decreto Legislativo núm. 29, prevé que «das Administraciones públicas puedan valerse, para la negociación descentralizada, de la actividad de representación o de asistencia de la Agencia, cuyas directivas deberán ser tenidas en cuenta en todo caso».

75 F. Carinci-M. T. CarincI, «La niforma del pubblico impiego. La privatizzazione del rapporto di lavoro", en Dir. Prat. Lav., 1993, núm. 15, XIV.

76 Véase M. Crestr, «Le procedure di formazione dei contratti collettivin, en Gior. Dir. Lav. Rel. Ind., 1993, 497 y ss.

77 Por lo que al personal de las regiones se refiere, es solicitado un previo informe de la Conferencia de Presidentes de las Regiones. Esta previsión ha motivado la Sentencia de la Corte Constitucional de 30 de julio de 1993, núm. 359, en Le Regioni, 1994, 1191 y ss., que, a solicitud de varias regiones, se ha pronunciado sobre la legalidad de la reforma en aquellos aspectos que inciden sobre el ordenamiento regional. La Corte, acogiendo algunas de las tesis promovidas por los recurrentes, ha considerado que los principios de la reforma relativos a la contractualización del empleo y a la imputación de la actividad negociadora a un único 
las disponibilidades financieras, así como los criterios generales respecto a los más importantes aspectos de la negociación; en la autorización del Gobierno ${ }^{78}$ para la suscripción del texto del convenio colectivo acordado entre la Agencia y las organizaciones sindicales y en el control de la autorización gubernativa que realiza la Corte de Cuentas, la cual verifica «la legitimidad y la compatibilidad económicas.

La mutación del conjunto de fuentes se corresponde con una asimismo radical mutación de la naturaleza jurídica de la relación. A excepción de las categorías que, como antes hemos recordado, permanecen reguladas por los respectivos ordenamientos, las relaciones de trabajo de los empleados de las Administraciones públicas son sustraídas al tradicional régimen público. Viene expresamente dispuesto que las relaciones individuales de trabajo y de empleo «son reguladas contractualmente» ${ }^{79}$ y que en esta materia las Administraciones públicas «operan con los poderes del empresario privado" ${ }^{80}$.

Consecuencia de tal mutación es la devolución del contencioso relativo a los empleados privatizados al juez ordinario del trabajo, con exclusión, por otra parte, de las controversias relativas a las materias sustraidas a la contractualización, sobre las que sigue teniendo competencia el juez administrativo ${ }^{81}$. El traspaso del juez administrativo al juez ordinario no es, sin embargo, inmediatamente operativo, sino que es aplazado hasta el momento en que concluya la fase transitoria destinada a promover el gradual paso del viejo al nuevo sistema. En virtud

organismo técnico no violaban la autonomía regional, pero si requerían «compensaciones adecuadas a la sustracción de poder normativo y contractual operado en relación con las Regiones". Las directivas conciliadoras de la Corte Constitucional han sido seguidas mediante la realización de algunas correcciones en el Decreto Legislativo núm. 29, en el sentido de la introducción de medidas «compensadoras» (informes sobre determinados actos, designación de componentes del comité directivo de la A.R.A.N.), que en parte han sido extendidas también a las Comunas y las Provincias.

${ }^{78}$ Por lo que se refiere a los convenios colectivos que afectan al personal de las regiones, el artículo 51.c), del Decreto Legislativo núm. 29, prevé que el Gobierno actúe previo acuerdo con las Administraciones regionales, expresado a través de la Conferencia de los Presidentes de las Regiones.

${ }^{79}$ Gran parte de la doctrina duda que el contrato individual tenga un espacio de operatividad efectiva (en tal sentido U. ROMAGNOL, La nevisione, cit., 237) en consideración, entre otros aspectos, a la previsión del articulo 49, c.2 del Decreto Legislativo núm. 29, según el cual «das Administraciones públicas garantizan a sus propios empleados... igualdad de trato contractual y, de todas formas, tratamientos no inferiores a los previstos en los respectivos convenios colectivos». De manera distinta, T. TREU, La contrattazione, cit., 8-9, considera que dicha normativa no excluye la posibilidad de tratamientos económicos edistintos en su aplicación concreta... también con carácter individual siempre, claro está, según criterios objetivosm.

${ }^{80}$ En tal sentido los artículos 2, c.3 y 4, c.1, respectivamente, del Decreto Legislativo núm. 29.

${ }^{81}$ Cfr. el articulo 68 del Decreto Legislativo núm. 29. 
de todo ello, tal como se ha dicho, la anterior normativa será integralmente sustituida por la disciplina de Derecho común del trabajo y por los convenios colectivos. Hasta tal momento, que coincide en el tiempo con la estipulación del segundo convenio colectivo posterior a la reforma, permanece en vigor la jurisdicción del juez administrativo.

\section{LOS ASPECTOS PROBLEMÁTICOS DE LA REFORMA. LA COHERENCIA DE LA APLICACIÓN DEL RÉGIMEN PRIVADO CON LOS PRINCIPIOS CONSTITUCIONALES}

Ante una reforma tan compleja y radical no podían faltar, y de hecho no faltan, aspectos problemáticos. Entre ellos, y como principal, la cuestión de su coherencia con los principios constitucionales. Se trata de una cuestión ya anticipada en el dictamen bastante crítico con el que, en 1992, la Asamblea General del Consejo de Estado expresó su propio parecer sobre el proyecto de ley que preveía la delegación al Gobierno para la revisión de toda esta disciplina ${ }^{82}$; y sobre el que, más recientemente, algunas actuaciones del juez administrativo ${ }^{83}$ han llevado a la Corte Constitucional a pronunciarse.

En el dictamen mencionado son expuestas las razones por las que el Consejo de Estado se opone a la privatización-contractualización del empleo público y a la consiguiente devolución del relativo contencioso al juez ordinario. Los argumentos giran en torno a la afirmación de una "diversidad ontológica» entre empleo público y trabajo privado y en torno a la consiguiente imposibilidad de una unificación de los respectivos regímenes, también a la luz de las disposiciones constitucionales. Respecto a esta última consideración, por otra parte, el Consejo de Estado no va mucho más allá del reclamo a la necesidad del respeto a la ureserva de ley del artículo 97 y de los inherentes valores de imparcialidad y de buen funcionamiento que deben presidir toda la acción y la organización administrativa», dando casi por des-

${ }^{82}$ Consejo de Estado, A. G., 31 de agosto de 1992, núm. 146, en Riv. Dir. Lav., 1993, III, 43 y ss., con comentario de A. AI.BANESE.

${ }^{83}$ Cfr. TAR Lazio, sez. I, ord. 23 de enero de 1996, 119, en Foro Italiano, 1996, III, 232 (relativa a la privatización y con especial referencia a los directivos), asi como TAR Lazio, sez. III, bis, ord. 5 de junio de 1996, núm. 1171. La primera cuestión ha sido declarada en parte infundada y en parte inadmisible por la Corte Constitucional con una sentencia (25 de julio de 1996, núm. 313) que todavía deja espacio a no pocas ambigüedades, tal como se precisará en la nota 87. 
contado que la Constitución no admita soluciones alternativas al modelo tradicional.

La diversidad estructural entre empleo público y trabajo privado aparece fundamentada en la circunstancia de que una gran parte de los empleados públicos (también de categorías inferiores a los dirigentes y a los directivos) está investida de funciones públicas y llamada a concurrir a la formación de la voluntad administrativa. De tal forma que «en todos estos casos parece imposible reducir la posición subjetiva de la Administración pública a la de un mero interés económico-privado en conseguir la realización de la prestación laboral por parte del empleado alli donde es preeminente el interés, público y general, del correcto ejercicio de las funciones en beneficio de la colectividad. Ello comporta necesariamente poderes de disciplina, de dirección, de control, de organización; en una palabra, poderes de supremacía que condicionan la posición subjetiva del empleado, degradando frecuentemente a intereses legitimos aquellos que en el ámbito privado serían derechos subjetivos».

Es más, según el Consejo de Estado también donde la prestación laboral no comporta en modo alguno ejercicio de funciones públicas, las elecciones fundamentales en materia de organización tienen que ser reservadas a la «autoridad» legislativa o administrativa. En consecuencia, pues, la disciplina privada del trabajo vendría a confluir con el poder discrecional de la Administración para organizarse y asegurar el buen e imparcial funcionamiento de la gestión pública: «no parece, por tanto, que con método nominal, sea consentido declarar privado aquello que está englobado en lo público y, en consecuencia, debilitar o separar la valoración del interés público que es fundamento de la actividad administrativas.

De la afirmación de la imposibilidad objetiva de una generalizada privatización del empleo público se extraen como lógicas consecuencias: un juicio negativo sobre la introducción de un auténtico sistema de negociación colectiva, que pueda prescindir de su recepción en un acto reglamentario del Gobierno con contenidos negociados con las organizaciones sindicales; la introducción del contrato individual que, de todas formas, frente a la permanente calificación pública de la relación, vendría a tener un valor puramente formal; así como la sustracción del contencioso a la jurisdicción exclusiva del juez administrativo.

De conformidad con la tradicional construcción, pues, el dictamen del Consejo de Estado parte de la especialidad del contexto en que se encuentra el trabajo y de la actividad para la que es utilizado (un aparato organizado para el ejercicio de 
funciones y el desarrollo de la actividad al servicio de la colectividad, en cuanto tal sometido a específicas reglas y, en primer lugar, a los principios de imparcialidad y buen funcionamiento), para deducir que el trabajo en las dependencias de las Administraciones públicas requiere una disciplina diferenciada del trabajo prestado a los privados, id est un régimen jurídico público.

Innegable la premisa, es preciso ver en qué medida resultan necesarias las consecuencias, no ya sólo de diferenciación de los contenidos materiales de la disciplina, sino, más radicalmente, de diversidad del régimen mismo de la disciplina y de la naturaleza jurídica de la relación.

En tal sentido, como se ha señalado anteriormente, las más recientes reflexiones doctrinales han puesto de manifiesto que las normas constitucionales explícita y directamente relativas al empleo público y a los empleados públicos no implican un particular régimen jurídico (público), sino que más bien requieren que los contenidos materiales de la disciplina resulten conformes a las prescripciones en ellas contenidos. Ello ocurre, por poner algún ejemplo (particularmente significativo en cuanto que se refiere a las materias que la misma reforma ha creído deber mantener en un régimen público desincorporándolas del área privatizada-contractualizada), con la selección para el acceso, la incompatibilidad y prohibición de acumulación de empleos públicos y otras actividades o cargos.

La Constitución prescribe el "concurso» para el acceso a los empleos, salvo los casos establecidos por la ley [art. 97.c).3]; establece, asimismo, que todos los ciudadanos de uno u otro sexo pueden acceder a los oficios públicos en condiciones de igualdad, según los requisitos definidos por la ley [art. c).1]. Frente a tales previsiones no parece solución obligada la devolución de la materia al circuito fuentes públicas/procedimientos administrativos/jueces administrativos. A decir verdad, lo que la Constitución efectivamente requiere es la utilización de un procedimiento concursal, la determinación por ley de los casos de derogación de tal procedimiento, la determinación por ley de los requisitos para el acceso en condiciones de igualdad. Pero dichas prescripciones no imponen un régimen público de concurso $y$, en particular, de los actos relativos al procedimiento de selección, sino que bien pueden ser satisfechas por normas apropiadas en un contexto que permanezca en aquel del Derecho privado ${ }^{84}$.

\footnotetext{
${ }^{84}$ Según M. Rusciano, Rapporto di lavorn, cit., 387, un sistema unitario para el trabajo público y privado podría ser encontrado en el recurso a la selección mediante colocación por las categorias más bajas y, para las restantes categorias, en base a un mecanismo concursal impregnado de modalidades rápidas y objetivas. En relación con este último aspecto, considera
} 
$\mathrm{Ni}$ es preciso oponer que de esta manera vendría comprometida la garantía de los privados y del interés público. No de los privados, que de cualquier modo encontrarian cobertura en las reglas puestas por la ley en cuanto a los requisitos para el acceso y el respeto a las condiciones de igualdad. Tampoco del interés público, porque la garantía de que la Administración se atenga a criterios de sana gestión bien puede ser satisfecha apostando (más que a su especial conformación del poder de selección del personal y, en consecuencia, su especial régimen de los actos de ejercicio de aquel poder y de las relativas técnicas de tutela) sobre mecanismos de control interno y sobre medidas de responsabilidad dirigidas a valorar la actividad realizada y eventualmente a sancionar los resultados negativos.

El mismo discurso vale para la materia de la incompatibilidad y de la prohibición de acumulación de empleos públicos y otras actividades, en cuanto se la quiera unir a la prescripción del artículo 98.c.1, de la Constitución sobre el servicio exclusivo a la Nación ${ }^{85}$. También aquí para garantizar la observancia del precepto constitucional, entendido sub specie de exclusividad de la prestación misma, no es estrictamente necesaria una disciplina reservada a las fuentes normativas unilaterales, a procedimientos administrativos y a la tutela del juez administrativo; como altetnativa, es suficiente una regulación legislativa de actuación de la prescripción constitucional a través de normas inderogables por la negociación colectiva e indisponibles por las partes.

Es preciso en este sentido hacerse cargo de la objeción, según la cual preceptos como los relativos al concurso o a la exclusividad de la prestación y, más en general, el servicio a la Nación, estando unidos al principio de imparcialidad y del buen funcionamiento de la organización y de la acción administrativa, requieren una disciplina y una actuación dirigida a tales fines (funcionalizada) y, por tanto, una connotación pública. Entra así en juego el artículo 97.1. ${ }^{\circ}$, y los interrogantes que lo acompañan. $¿$ El hecho de que el trabajo se inserte en un contexto y se dedique a una actividad inspirada en los principios de imparcialidad y

\footnotetext{
Rusciano que đda idea de una selección concursal mucho más atenta e imparcial, capaz de hacer surgir las verdaderas aptitudes profesionales de los individuos, no es ciertamente extraña al sector privado, donde en la práctica de los últimos años se registra el recurso a agencias especializadas en la selección de personal, conducidas a través de procedimientos seguramente imparciales».

85 Una lectura del artículo 98, c.1, de la Constitución que reduzca el «servicio exclusivo a la Nacións a la mera cuestión de la exclusividad de la prestación profesional suscita, por otra parte, grandes reservas: vid. en este sentido a C. PINEL, "La pubblica amministrazione", Commentario della costituzione fondato da Branca e continuato da Pizzonusso, Bolonia-Roma, 1994, 413 y ss.
} 
buen funcionamiento exige un régimen especial? ¿El precepto constitucional impone que la regulación del trabajo esté reservada a las fuentes legislativa y reglamentaria y que en el ámbito de la relación de empleo la Administración actúe como autoridad pública?

Sostiene el Consejo de Estado que admitiendo la negociación colectiva del Derecho común, a causa de la intrínseca debilidad de la parte pública y de su naturaleza política, vendría comprometida la garantía de que la regulación del empleo responde al objetivo, de interés público y general, del eficiente, económico e imparcial funcionamiento del aparato. Y, paralelamente, que análogo resultado negativo se obtendría donde se midiese la posición de la Administración como un umero interés económico-privado en conseguir la realización de la prestación laboral por parte del empleadon.

Frente a tales preocupaciones, la experiencia madurada en el pasado más o menos reciente demuestra la incapacidad del modelo público de empleo para garantizar el buen funcionamiento de la Administración, actualmente entendido como eficacia y eficiencia ${ }^{86} \mathrm{y}$, al mismo tiempo, garantizar la misma imparcialidad. De esta manera se ha trazado un círculo vicioso: por un lado, la ineficiencia y la ineficacia han prejuzgado la imparcialidad; por otro, la concepción puramente formal e hiperlegalista de la imparcialidad ha determinado la ineficiencia y la ineficacia. Basta citar un pasaje relativo a un instituto específico y una conclusión general contenida en la relación de una comisión de estudio ${ }^{87}$ que, en el seno del Departamento para la Función Pública, se ha ocupado durante los años 1993-94 de la materia del personal público. A propósito del acceso y de la selección del personal ha destacado que «la implantación absurdamente garantista de los mecanismos de los concursos ya parece tener, como primer y frecuentemente único objetivo, la garantía de igualdad de tratamiento de aquellos que buscan trabajo en la Administración pública y no aquel de encontrar a la persona más apta para ocupar un puesto específico. Ello no ha impedido en el pasado las prácticas clientelares... pero ha justificado todas las ineficiencias... y, sobre todo, los espantosos retrasos con que son cubiertos los puestos vacantes». La conclusión general es que la utilización

${ }^{86} \mathrm{Cfr}$. U. ALLEGRETTI, "Imparzialità e buon andamento della pubblica amministrazione», en Dig. discipline pubbl, vol. VIII, Turin, 1993, 131 y ss.

${ }^{87}$ La relación está publicada en Presidenza del Consiglio dei Ministri-Dipartimento per la Funzione pubblica, La riforma della pubblica amministrapione (Atti dalle Commissioni e dei Comitati di studio), vol. II, Nuovo rapporto di lavoto del personale delle amministrazione pubbliche, Roma, Istituto Poligrafico e zecca delio Stato, 1994,9 y ss. 
de los instrumentos públicos, por vía de las reglas y de los vínculos impuestos a la discrecionalidad de la Administración, ha terminado por ser orientada esencialmente a la garantía de la abstracta legalidad de los actos y de los procedimientos y no ya al eficaz y eficiente empleo del personal. Ello resulta completamente inidóneo y disfuncional respecto a los fines que deberían presidir la actividad para la que es aplicado.

Por otra parte, tal como habíamos señalado antes, la hipótesis alternativa de una utilización de las reglas comunes del trabajo no excluye la posibilidad de tener en cuenta la especificidad del sujeto Administración pública, que es lo que ha hecho la reciente legislación reformadora: precisamente en consideración a tal especificidad, han sido fijados los límites y vínculos de la negociación colectiva a través del establecimiento de materias que están excluidas y de normas inderogables; se ha disciplinado un procedimiento con carácter público para la negociación; han sido individualizados algunos principios a los que deben someterse los contratos individuales; han sido previstos mecanismos de verificación de la negociación, en particular en lo que se refiere a los costes; han sido previstos controles y responsabilidades por los rendimientos y resultados de la gestión financiera, técnica y administrativa, incluidas las decisiones organizativas y de gestión del personal.

Por ello no está desatendida la orientación hacia el buen funcionamiento y la imparcialidad proclamada en el artículo 97 de la Constitución, que en el anterior sistema había encontrado insuficiente traducción en la aplicación al trabajo de reglas del Derecho administrativo. Precisamente para lograr aquellos objetivos se ha querido extender el Derecho común del trabajo, aunque con aquellos límites y aquellas sagacidades destinadas a evitar que la Administración haga un uso equivocado y, por tanto, perjudicial del buen funcionamiento y de la imparcialidad. Se podrá discutir sobre los límites y sobre las especialidades tal como han sido definidas e individualizadas por el legislador; pero éste no es el aspecto que interesa. Importa, sobre todo, subrayar que en principio una opción como la que estamos examinando no contrasta con el artículo $97.1 .^{\circ} \mathrm{c}$ de la Constitución.

$\mathrm{Ni}$ parece que una distinta conclusión deba alcanzarse cuando la atención venga específicamente concentrada en los empleados que ejercen funciones públicas ${ }^{88}$. El modo y la forma en la que

${ }^{88}$ Según C. PINELu, «Profili costituzionali della riforma del rapporto di pubblico impiego», en Nomos, 1990, núm. 3, 39 y ss., estando las conexiones entre organización de los oficios públicos y regulación de las funciones de los titulares de la potestad pública, la disciplina relativa 
es regulado y gestionado el trabajo influye en la cantidad y cualidad de todo aquello que la Administración "produce», procedimientos administrativos y otros actos, operaciones materiales, bienes, servicios y prestaciones varias. Las consecuencias negativas que la colectividad sufre por el mal funcionamiento de la Administración no son de menos peso e importancia cuando sea interesada la preparación de prestaciones materiales, la realización de trabajos o la erogación de servicios que cuando se trata del ejercicio de funciones públicas. Ni se ven las razones por las que, para garantizar la consecución de una idónea prestación laboral por parte de un empleado encargado del ejercicio de funciones públicas, sea necesario un instrumental distinto de aquel que es válido para un operador de los servicios sanitarios, de los servicios asistenciales o de la escuela.

También se ha observado, aunque esta vez con una particular atención a los dirigentes, que la libertad de elección que comportan los poderes empresariales, y sobre todo el «régimen de terminación de la relación de trabajo, centrado en el área contractual privada en el deterioro de la relación de confianza», incidirían negativamente sobre el imparcial y eficiente desarrollo de las funciones atribuidas a una determinada categoria de personal, prejuzgando la autonomía y la independencia en el ejercicio de las tareas de gestión que la misma ley de reforma les ha reservado ${ }^{89}$. Se apela así, aunque esta vez a favor de los

a los empleados titulares de potestades públicas no podría ser confiada a la negociación al afectar a la reserva de ley del artículo 97 de la Constitución. Tal reserva habría sido puesta para encarcelar el principio democrático que debe presidir el procedimiento de elección de los criterios de organización y acción de la Administración pública, que la misma Constitución funcionaliza al servicio de la colectividad con el reclamo a los principios de imparcialidad y buen funcionamiento. Al respecto se subraya lo que antes hemos afirmado: distinta es la cuestión de la reserva de ley prevista en orden a la organización administrativa por el arcículo 97 de la Constitución; la cuestión de los instrumentos infralegales de regulación de tal materia e, incluso, la cuestión del régimen jurídico de la actividad de organización y de la relación de empleo. El artículo 97 de la Constitución requiere seguramente una cobertura legal de la materia, pero no exige necesariamente una regulación infralegal unilateral y pública, ni tampoco implica, inexcusablemente, una connotación pública y unilateral de la actividad organizativa y de la relación de trabajo de los sujetos encargados del ejercicio de funciones públicas.

${ }^{89}$ En tal sentido el TAR Lazio, ord. 23 enero de 1996, núm. 119 cit., con la sentencia núm. 313 de 1996 cit. La Corte Constitucional ha negado que la aplicación del régimen privado represente un perjuicio para la imparcialidad de los empleados públicos, en particular para los dirigentes; paralelamente ha excluido que como garantia de la imparcialidad misma sea necesario un estatuto público. Según la Corte, «la elección entre uno u otro régimen corresponde a la discrecionalidad del legislador, para ejercitarse en vista a la más eficaz y armónica realización de los fines y de los principios que conciernen a la actividad y a la organización de la Administración públicas. En virtud de tales consideraciones, el juez constitucional ha considerado infundada la cuestión planteada por el TAR Lazio. Por otra parte, es preciso subrayar que la sentencia motiva la conclusión en que, en el asunto referente a los dirigentes, el Decreto Legislativo núm. 29 habría limitado «el espacio negociador casi exclusivamente al tratamiento económico», que no consentiría «una regulación contractual de la responsabilidad disciplinaria» 
empleados, a las ugarantías más firmes que están implicadas en la relación pública de servicion. Al respecto debemos retomar las consideraciones anteriormente desarrolladas y señalar, por un lado, que el Derecho común del trabajo no está provisto de garantías eficaces (que, de cualquier modo, pueden ser sopesadas de forma distinta por el legislador en relación a los casos ${ }^{90}$ ) y, por otro, que la disfuncionalidad de la relación pública de servicio radica, precisamente, en haber sido orientada más hacia un abstracto garantismo que hacia el eficiente y eficaz empleo de la fuerza del trabajo.

\section{7. (continuación) ASPECTOS CRÍTICOS SOBRE ALGUNOS LIMITES Y MODALIDADES DE LA CONTRAC'TUALIZACIÓN DEL EMPLEO}

Aunque pueden considerarse infundadas las objeciones más radicales basadas en la tesis de que la Constitución impondría un régimen público de empleo con las Administraciones públicas, no faltan todavía numerosos puntos de la nueva normativa que suscitan reservas.

Tal como se ha visto, el ámbito de aplicación de la reforma comprende todas las Administraciones públicas no económicas con excepción de algunas categorías de empleados. Son evidentes las razones que han inducido a la exclusión del personal militar, de policía y de la magistratura, en la medida en que se trata de funciones que representan, aunque sea simbólicamente, el núcleo duro del poder estatal y para cuyo desenvolvimiento se requieren vínculos y garantías completamente particulares. Pero ¿qué decir

y, en definitiva, que la disciplina de la relación de trabajo de esta categoría se debería colocar (a mitad de camino entre el modelo público y el privadom. Todas estas afirmaciones se muestran muy inexactas desde el momento en que el espacio negociador para la categoria de los dirigentes no está ciertamente limitado como la Corte pretendería (la demostración más evidente viene dada por el contenido del primer convenio para los dirigentes relativo al compartimiento regiones y entes locales). En ello radica la ambigüedad de esta sentencia. Si la Corte hubiera querido evitar un pronunciamiento de inconstitucionalidad, habría dado un golpe traumático a la entera reforma; pero al mismo tiempo habría querido amonestar al legislador solicitándole una revisión normativa que asegure una mayor cobertura legislativa (sustracción a la negociación) de aquellos aspectos en que la relación de oficio implica el desarrollo de funciones que participan del momento organizativo de la Administración pública; hasta realizar «una sucesiva verificación, siempre posible en el futuros.

${ }^{0}$ En la relación presentada por la Comisión de estudio citada en la nota 87 se observa respecto a la clase dirigente que «las garantías respecto a la posible y deteriorante intromisión de la política que, por otra parte, es discinta del legítimo uso de la dirección politica, se encuentran... sobre todo en la absoluta publicidad de los consiguientes resultados, que sirven para distinguir entre las remociones discriminatorias y aquellas justificables en base al interés de la colectividad, así como es percibido por los gobernantes del momento» (pág. 27). 
del personal empleado en la Banca de Italia, en la Comisión Nacional para la Sociedad y la Bolsa y en la Autoridad garantizadora de la competencia en el mercado? Si la razón de la exclusión misma está en las particulares exigencias funcionales y organizativas de tales Administraciones, para cuya salvaguardia se hubiera querido asegurar una regulación y gestión del trabajo reservada a las autónomas y unilaterales determinaciones de aquellas Administraciones, quedaría poco claro por qué la exclusión no se ha extendido también a otros aparatos destinados a no menos importantes y delicadas funciones (pensemos, por ejemplo, en las cancillerias judiciales destinadas a funciones auxiliares del ejercicio de las funciones jurisdiccionales). Probablemente, sin embargo, es otra la efectiva razón de la exclusión; no se refiere tanto al régimen jurídico de la relación de empleo (por lo demás, las leyes que disciplinan la CONSOB y la Autoridad garantizadora de la competencia admiten la incorporación de personal con contrato de trabajo privado) sino más bien a las modalidades organizativas de la contratación y de las relaciones sindicales. Es decir, se ha querido preservar la autonomía de algunas Administraciones de alto perfil de la rigidez y de los condicionamientos de un modelo fuertemente centralizado, que tiene una carga altamente uniformadora pero que, a pesar de todo, continúa garantizando importantes poderes e influencias a las organizaciones sindicales ${ }^{91}$. El haber mantenido fuera algunas estructuras privilegiadas evidencia el conocimiento por parte del propio legislador de los defectos indicados, cuyo precio corresponde pagar a la generalidad de las Administraciones públicas.

Notable perplejidad ha suscitado, por otra parte, la diferenciación de régimen interno entre los dirigentes según la categoría en la que aparezcan encuadrados. Al prever la aplicación del Derecho común del trabajo al personal con la cualificación de «dirigente», el legislador ha considerado, más que idónea, preferente, la aplicación de los instrumentos privados también a los que estén encargados de funciones dirigenciales. Ante ello es preciso preguntarse cuáles han sido las razones que presiden el mantenimiento de un régimen público para los «dirigentes generales»y.

No parece que se pueda decir que en la base de la elección esté la consideración de las peculiares y reforzadas garantías que derivan de la aplicación de un régimen público, ya sea a favor

91 Cfr. S. CASSESE, (Ull sofisma della privatizzazione del pubblico impiego", en Riv. It. Dir. Lav., 1993, I, 305-309. 
del empleado, ya sea a favor de la Administración. A decir verdad, si se tratara de una cuestión de más adecuadas garantias aseguradas por el régimen público, ello equivaldria a reconocer la estructural inidoneidad de la solución adoptada para el otro grupo en que se divide la clase dirigente. Por otra parte, parece intrínsecamente contradictoria la idea de que sea necesario un reforzamiento de las garantías para la alta dirigencia, que no puede ser otra que el lazo de confianza con los órganos de dirección y de gobierno. En definitiva, pues, el propio Decreto Legislativo núm. 29 contempla la posibilidad de que puestos como dirigente general puedan ser ocupados por personal que se incorpore mediante un contrato de Derecho privado, desmintiendo, de esta manera, la necesaria correspondencia entre ejercicio de aquellas funciones y una relación de empleo sometida a un régimen público.

Parece bastante más real pensar que con la diferenciación de regímenes jurídicos se haya querido, más bien, dar un distinto carácter e identidad a una restringida elite de funcionarios, sustrayéndola del conjunto en un sistema que terminaría por homologarla con el resto del personal. Pero, tal como ha sido destacado, si éste era el objetivo, habría sido suficiente para conseguirlo con la mera exclusión de la fuente colectiva, dejando en vigor la contractualización de la relación ${ }^{92}$.

A decir verdad, los mismos intentos de evitar una homogeneización con el resto del personal han sido adoptados también para los dirigentes en régimen privado. En efecto, para ellos ha sido contemplada, dentro de cada uno de los compartimientos, un área de negociación distinta y separada de aquella relativa al personal no dirigente. $\mathrm{E}$, incluso al mismo tiempo, ha sido prevista la necesaria implicación en la negociación nacional del área dirigencial de las "confederaciones más representativas» de los trabajadores en general (prescindiendo de la representatividad del personal comprendido en el área). Ello es criticable desde el momento en que de esta forma las organizaciones representativas de la generalidad de los empleados influyen sobre la determinación del tratamiento de aquellos dirigentes a los que la ley asigna importantes funciones en materia de organización y gestión del trabajo y desde el momento en que en las relaciones sindicales, a nivel de singulares Administraciones, constituyen institucionalmente una contraparte de las organizaciones sindicales ${ }^{93}$.

${ }^{92}$ Cfr. A. ZoppoLl, «La dirigenza nel pubblico impiego "privatizzato"》, en L'impiego pubblico nel Diritto del lavoro, cit., 75.

${ }_{93}$ A propósito de la presencia de las confederaciones en la negociación para las áreas dirigenciales M. BARBIER-M. G. Garofalo ("La contrattazione collettivan, en Il lavoro alle 
Más allá de esto, es todavía preciso resaltar que para los dirigentes privatizados los tratamientos estructurales de la relación de trabajo resultan ambiguos y en ciertos casos contradictorios. Se considera que uno de los institutos más significativos y peculiares de la relación de trabajo de los dirigentes es la «responsabilidad» por el resultado de la actividad desarrollada en los oficios que tienen a su cargo ${ }^{94}$; en caso de valoración negativa pueden aplicarse diversas medidas, hasta el despido. A este respecto ha dictado el legislador una disciplina detallada, rodeando de amplias garantías la valoración de la actividad desarrollada por el dirigente y la aplicación de las consiguientes medidas. Sin embargo, no se ha ocupado, ni siquiera mínimamente, de la cuestión general de la terminación de la relación de trabajo. De esta forma, el dirigente que, por un lado, goza de amplias garantías respecto a las medidas de actuación de la responsabilidad dirigencial está, por otro. lado, sujeto a una disciplina legal de la extinción de la relación que permite la separación por el puro y simple menoscabo de la relación de confianza.

Otro punto crítico del nuevo sistema es el que se refiere a la definición de las materias sustraídas a la negociación.

Desde los primeros comentarios y desde los primeros debates dedicados a la Ley núm. 421 y al Decreto Legislativo núm. 29 han sido muchas las voces criticas ${ }^{95}$ que se han escuchado sobre la definición de la línea que marca los confines entre el área sujeta a la disciplina de Derecho común y las materias reservadas a las fuentes públicas unilaterales, para las que en conjunto permanece el régimen de Derecho administrativo. Se considera que dicha cuestión encuentra un importante escollo en materia de tutela jurisdiccional, en la medida en que la reserva a las fuentes públicas y el mantenimiento de ciertas materias en régimen de Derecho administrativo implica, según el dictado de la Ley núm. 421 y el Decreto Legislativo núm. 29, la sustracción a la jurisdicción del juez ordinario - de otra manera competente para el contencioso del trabajo- de las controversias relativas a aquellas materias.

Las críticas sobre este aspecto han insistido en la escasa claridad de las expresiones usadas para la definición del ámbito sustraído a la privatización-contractualización, hasta tal punto que resultaba incierto y contradictorio si determinadas materias o institutos, también de notable importancia (entre ellas la respon-

\footnotetext{
dipendenze, cit., 707), para quienes se prevé un papel de «contraparte añadida» respecto a las organizaciones sindicales de los dirigentes.

${ }^{94} \mathrm{Cfr}$. el artículo 20 del Decreto Legislativo núm. 29.

95 Cfr. por todos a S. CASSESE, II sofisma della privatizzazione, cit., 287 y ss.
} 
sabilidad disciplinaria), debían ser comprendidos o no en un determinado ámbito. A tal fin, los decretos correctivos ${ }^{96}$ han intervenido oportuna y explícitamente afirmando la pertenencia al área privatizada-contractualizada de institutos cuya colocación ${ }^{97}$ era más o menos dudosa.

Este hecho, si bien ha atenuado el problema, no lo ha resuelto del todo, en la medida en que el elenco de las materias sustraídas a la privatización-contractualización está contenido en la propia ley de delegación. Así, la solución adoptada por el legislador delegado en vía de interpretación de aquel elenco, no permanece al margen de posibles contestaciones sobre el plano de la legitimidad constitucional por su contraste con las prescripciones de la ley de delegación ${ }^{98}$. Por eso, para resolver radicalmente el problema parece, pues, indispensable una nueva y más clara regulación sobre este punto.

Esta intervención no se limita únicamente a la exigencia de evitar los inconvenientes que sobre el plano aplicativo podrían derivar de la incerteza sobre la línea de demarcación de los confines entre área en régimen privado y área en régimen público (piénsese en los giros sobre la tutela jurisdiccional ${ }^{99}$ ). Responde también a la exigencia de repensar en la dislocación misma de aquella línea que, al ser diseñada por la Ley núm. 421, aparece, más allá de su escasa claridad, poco apropiada.

Pasamos ahora a otra crítica ya avanzada por los primeros comentaristas de la reforma: el no haber realizado una plena y completa privatización, dando más bien vida a un sistema híbrido, en parte de Derecho público y en parte de Derecho privado. También para este aspecto los Decretos Legislativos correctivos núm. 470 de 10 de noviembre de 1993 y núm. 546 de 23 de diciembre de 1993 han tratado, en la medida de lo posible, de aportar remedios reduciendo el área de la relación de trabajo sometida a reglas públicas; pero sin poder, todavía, poner en discusión el dictado de la letra c), del c.1, del artículo 2 de la Ley núm. 421.

Esta norma traza de manera enrevesada y sinuosa la línea delimitadora de los confines entre aquello que está sujeto a un

96 La ley de delegación legitimaba al Gobierno para dictar disposiciones correctivas de los decretos legislativos hasta el 31 de diciembre de 1993.

${ }^{97}$ En tal sentido el texto del artículo 59 y del artículo 68 del Decreto Legislativo núm. 29 ha sido innovado por el Decreto Legislativo núm. 546 de 23 de diciembre de 1993.

${ }^{98}$ En este sentido cfr. G. AlBENZIO, «ll punto sulla privatizzazione del pubblico impiego dopo gli interventi correttivi del d. leg. 29/93", en Riv. It. Dir. Lav., 1994, I, 396 y ss.

${ }_{99}$ Para lo cual reenviamos a D. Borghesi, «La giurisdizione», en Il lavoro alle dipendenze, cit., 1123 y ss.; cfr., por otra parte, A. CORPACI, «La tutela giurisdizionale dei pubblici dipendenti», en Gior. Dir. Lav. Rel. Ind., 1993, 605 y ss. 
régimen público y aquello sometido a un régimen privado. Por un lado, si bien la privatización de la relación de trabajo está ciertamente sometida a directivas fundamentales, son mantenidas en régimen público algunas materias directamente pertenecientes a dicha relación. Por otro lado, si bien en principio la organización permanece sometida a un régimen público, es legible al mismo tiempo un límite en la aplicación de aquel régimen: en efecto, la reserva se refiere a «los principios fundamentales de organización de los oficios», pudiéndose entonces considerar que bajo tal umbral encuentra aplicación un régimen propiamente haciendalista.

La cuestión se agrava por el hecho de que a la reserva de ley (a la sustracción a la contractualización) el legislador ha hecho corresponder, en el plano de la tutela, la exclusión de la jurisdicción del juez ordinario, que de otro modo sería competente para las controversias de trabajo de los empleados privatizados. El sistema de jurisdicción única (del juez administrativo) ha sido sustituido por un sistema dualista donde la distribución de la jurisdicción entre juez ordinario y juez administrativo se fundamenta en la definición de las materias pertenecientes a uno u otro juez. Al juez ordinario compete el contencioso del trabajo referido a las materias sujetas al régimen privado, con exclusión de aquellas mantenidas en régimen público y confiadas al juez administrativo.

El hecho mismo de haber introducido un sistema de jurisdicción repartida es ya de por sí criticable. Tanto más cuanto, tal como se ha visto anteriormente, resulta discutible la individualización de las materias pertenecientes a la competencia de uno u otro juez.

Desde este punto de vista, los problemas de esta cuestión dependen no sólo de la imprecisa o equívoca definición de las materias sustraídas a la jurisdicción del juez ordinario, sino que su principal defecto radica en que el elenco de las materias sustraídas ha sido en realidad concebido y formulado con referencia a las fuentes destinadas a su regulación (sustracción de la negociación colectiva y reserva a las fuentes unilaterales públicas) y, después, mecánicamente aplicado al reparto de jurisdicciones. Con soluciones que en algunos casos aparecen particularmente enigmáticas.

Por el mero hecho de instituir un sistema de jurisdicción repartida, la reforma nace con un vicio congénito. Dicho vicio de origen, que aparece en la ley de delegación y que los decretos correctivos han intentado superar, aunque no han podido eliminar, sólo es posible remediarlo con una revisión normativa que 
concentre todas las controversias referentes a la relación de empleo de los empleados de las Administraciones públicas en la jurisdicción del juez ordinario.

Para tal fin, por otra parte, no parece suficiente romper el paralelismo entre reserva de ley y sustracción a la cognición del juez ordinario. La cancelación de la previsión que excluye del ámbito devuelto a la jurisdicción ordinaria las materias cuya regulación permanece reservada a la ley, o bien a los actos normativos o administrativos, no es suficiente para resolver todos los problemas. En efecto, la reserva de ley, tal como ha sido concebida por la Ley núm. 421 de 1992, significa en realidad el mantenimiento de las materias catalogadas en un régimen público; $y$, desde el momento en que entre aquellas materias algunas son intrínsecas a la relación de trabajo, dos son las hipótesis posibles: - bien que, una vez reconducidas a la jurisdicción del juez ordinario las controversias relativas a las materias intrínsecas a la relación de trabajo pero mantenidas en régimen público, se considere también ampliada su cognición a procedimientos administrativos y a la tutela de los intereses legítimos; o, en caso contrario, para aquellas controversias se abre el problema del reparto entre juez ordinario y juez administrativo según la naturaleza de las situaciones jurídicas hechas valer.

Para evitar incertezas y complicaciones es, por tanto, indispensable la revisión de la línea de separación de los confines entre el área sometida al régimen público y el área privatizadacontractualizada, concentrando en esta última todas las materias y las instituciones pertenecientes a la relación de trabajo.

El nuevo modelo de tutela jurisdiccional suscita amplias reservas en los aspectos anteriormente resaltados; no ciertamente por la eventualidad, por algunos reseñada ${ }^{100}$, de que la atribución de las controversias de trabajo al juez ordinario implique el menoscabo de la tutela de los intereses legítimos o, de todas formas, una disminución de las garantías ofrecidas por el juez. Efectivamente, a decir verdad, los espacios de valoración discrecional en el área contractualizada que pueden corresponder a la Administración-empresaria no son reconducibles al ejercicio de potestades públicas, configurando más bien ejercicio de comunes poderes empresariales. Y tal ejercicio es tutelado por el juez ordinario, ya sea bajo el perfil del respeto de la normativa y de eventuales reglas recogidas en los convenios colectivos, ya sea

${ }^{100}$ Cfr. en este sentido el dictamen de la A. G. del Consejo de Estado anteriormente cit.; véase también C. CеСCHELL, «Tutela giurisdizionale dei diritri del pubblico impiegato e poteri del giudice ordinariom, en Lav. Dir., 1994, 31 y ss. 
bajo el perfil de la observancia de los principios de corrección y buena fe.

Finalmente, entre los aspectos más complejos y delicados de la reforma se encuentra el relativo a la estructura, a los sujetos y al procedimiento de la negociación colectiva.

Ante todo, la atribución a un único organismo de la representación de todas las Administraciones públicas en sede nacional responde a una confusa configuración de tal organismo, que oscila entre el papel de agente negociador en posición de dependencia del Gobierno y aquel de estructura al servicio del completo sistema de las Administraciones públicas, pero con elementos claramente indicativos de un desequilibrio en el primero de los sentidos apuntados.

A todo ello es preciso añadir una relación puramente jerárquica entre la negociación colectiva nacional y la descentralizada. Por los espacios dejados a la descentralización se mide el grado de flexibilidad del sistema y el grado de autonomía de los distintos sujetos que negocian. Al respecto debemos decir que la reforma, al no poner límites legales a la descentralización, deja abierta la posibilidad de que en la práctica se encuentre un punto de equilibrio entre las contrapuestas exigencias, evitando incontroladas presiones disgregadoras, así como una regulación centralizadora y uniformadora. Pero este deseable evento depende completamente de la negociación nacional, a quien corresponde la definición de las materias y de los límites de la descentralizada. Se debe añadir, por otra parte, que sobre la negociación a nivel local pesa un papel de dirección impropiamente atribuido a la A.R.A.N., a cuyas directivas las Administraciones públicas deben conformar su actuación.

Al final, en el procedimiento de negociación se ha mantenido el poder general de autorización del Gobierno para la estipulación de los convenios colectivos, también en los relativos a compartimientos de personal no estatal. Y se ha mantenido el control de la Corte de Cuentas, que extiende, no ya sólo al aspecto financiero, sino también a la legalidad/legitimidad de los convenios y del procedimiento entero ${ }^{101}$ (alli comprendidos todos los actos preparatorios $\mathrm{y}$, entre ellos, las directivas impartidas por el Presidente del Consejo a la A.R.A.N.).

El modelo de negociación colectiva está, por tanto, fuertemente hétero-regulado e inspirado en una acentuada centraliza-

101 Cfr. Corte Conti, sez. controllo, primo collegio, 6 de mayo de 1995, en Riv. It. Dir. Lav., 1996, III, 5 y ss., con una presentación de A. Albanese, ull controllo della Corte dei Conti sull'autorizzazione governativa alla sottoscrizione del contratto collettivo dei dipendenti dei Ministerio. 
ción. Ello representa una gran contradicción interna en el sistema. Si se considera que se ha pretendido la introducción de los principios y de las reglas del Derecho privado para liberar y maximizar la autonomía negociadora y la capacidad de gestión de las Administraciones públicas, se deberá convenir que tal objetivo corre el riesgo de frustrarse por una acentuada héteroregulación, centralización y jerarquización del modelo de negociación. Las justificaciones dadas al respecto vuelven a hacer referencia a razones de control del gasto, así como a la circunstancia de que los recursos financieros de que disponen las distintas Administraciones públicas provienen, en mayor o menor medida y según los cașos, de transferencias estatales. Se añade, además, una razón más sólida unida a la actuación de una reforma que, por su profundidad y complejidad, exigiría ser guiada unitariamente desde el centro.

La bondad de tales argumentos es discutible.

En cuanto a la cuestión del control del gasto, además de señalar que se está haciendo referencia-a un escenario en vía de superación dada la tendencia al abandono del sistema de finanzas derivadas y a la acentuación de los niveles de autonomía de los distintos sujetos de Administración pública, es preciso señalar, de todos modos, que la negación o la excesiva restricción del espacio para autónomas determinaciones implica responsabilidad, produce extrañeza respecto a los vínculos impuestos e induce a eludirlos; de esta manera contribuye a agravar, más que a resolver, el problema de la contención y de la racionalización del gasto.

En segundo lugar, y centrándonos en las innovaciones que requiere la reforma, se ha observado que no se puede realizar un proceso destinado a dejar más dinámica y flexible la organización y la gestión del trabajo, dada su contradicción, una elevada tasa de hétero-regulación, una práctica de dirección y una uniformidad de disciplinas.

La necesidad de poner remedio, entre otros, a los defectos señalados ha sido advertida también en la sede política parlamentaria. En la sesión del 4 de julio pasado en el seno de la Comisión de Trabajo de la Cámara ${ }^{102}$, el Ministro para la Función Pública, ilustrando las líneas programáticas del Gobierno en materia de empleo público, ha anunciado un proyecto de ley que se propone resolver los problemas de los que hemos hablado: revisión (reducción) de las materias sometidas al régimen público, unificación bajo el régimen privado de toda la clase dirigente, con-

102 Cfr. Atti parlamentari, Camera dei Deputati, XIII Legislatura, Commissione XI, núm. 3, 69 y ss. 
centración de la jurisdicción en manos del juez ordinario, superación de la acentuada tasa de rigidez y de centralización, articulación más flexible de la negociación y valoración de la negociación descentralizada.

En conclusión: la reforma no es todavía plenamente operativa y ya se anuncia una intervención modificadora. Ello nos lleva a la advertencia anteriormente avanzada y confirmada de todo lo dicho, no sólo acerca de la viabilidad del cambio sino también acerca de sus todavía imprecisos resultados. 